NBER WORKING PAPER SERIES

\title{
FISCAL SPACE AND THE AFTERMATH OF FINANCIAL CRISES: HOW IT MATTERS AND WHY
}

\author{
Christina D. Romer \\ David H. Romer \\ Working Paper 25768 \\ http://www.nber.org/papers/w25768 \\ NATIONAL BUREAU OF ECONOMIC RESEARCH \\ 1050 Massachusetts Avenue \\ Cambridge, MA 02138 \\ April 2019
}

We are grateful to James Church for assistance with data, to Olivier Blanchard, Janice Eberly, Patrick Honohan, Lars Jonung, Philip Lane, Edward Nelson, Maurice Obstfeld, James Stock, Phillip Swagel, Brookings Panel participants, and seminar participants at the University of California, Berkeley for helpful comments, and to the University of Edinburgh for support during early stages of this project through the UK Economic and Social Research Council, award reference ES/L990633/1. The views expressed herein are those of the authors and do not necessarily reflect the views of the National Bureau of Economic Research.

NBER working papers are circulated for discussion and comment purposes. They have not been peer-reviewed or been subject to the review by the NBER Board of Directors that accompanies official NBER publications.

(C) 2019 by Christina D. Romer and David H. Romer. All rights reserved. Short sections of text, not to exceed two paragraphs, may be quoted without explicit permission provided that full credit, including $\odot$ notice, is given to the source. 
Fiscal Space and the Aftermath of Financial Crises: How It Matters and Why

Christina D. Romer and David H. Romer

NBER Working Paper No. 25768

April 2019

JEL No. E32,E62,G01,N10,N20

\begin{abstract}
$\underline{\text { ABSTRACT }}$
In OECD countries over the period 1980-2017, countries with lower debt-to-GDP ratios responded to financial distress with much more expansionary fiscal policy and suffered much less severe aftermaths. Two lines of evidence together suggest that the relationship between the debt ratio and the policy response is driven partly by problems with sovereign market access, but even more so by the choices of domestic and international policymakers. First, although there is some relationship between more direct measures of market access and the fiscal response to distress, incorporating the direct measures attenuates the link between the debt ratio and the policy response only slightly. Second, contemporaneous accounts of the policymaking process in episodes of major financial distress show a number of cases where shifts to austerity were driven by problems with market access, but at least as many where the shifts resulted from policymakers' choices despite an absence of difficulties with market access. These results may have implications for the conduct of policy both in normal times and in the wake of a financial crisis.
\end{abstract}

\author{
Christina D. Romer \\ Department of Economics \\ University of California, Berkeley \\ Berkeley, CA 94720-3880 \\ and NBER \\ cromer@econ.berkeley.edu \\ David H. Romer \\ Department of Economics \\ University of California, Berkeley \\ Berkeley, CA 94720-3880 \\ and NBER \\ dromer@econ.berkeley.edu
}


There is enormous variation in macroeconomic performance in the aftermath of financial crises. Recent research finds that the amount of fiscal space countries have before a crisis-that is, the room policymakers have to take action-appears to be an important source of this variation. Countries with low debt-to-GDP ratios when a crisis strikes typically face only modest downturns, while countries with high debt ratios generally suffer large and long-lasting output losses (Jordà, Schularick, and Taylor 2016; Romer and Romer 2018). The apparent mechanism behind this correlation is the obvious one: countries that begin a crisis with ample fiscal space take much more aggressive fiscal action. This includes both financial rescue-bank bailouts, loan and deposit guarantees, and recapitalization of financial institutions-and conventional fiscal stimulus-tax cuts and spending increases (Romer and Romer 2018).

Our primary goal in this paper is to understand why a country's fiscal response to a crisis depends on it prior debt-to-GDP ratio. One possibility is that it reflects constraints imposed by market access. Countries with a higher debt ratio may be less able to take aggressive fiscal action or must move more quickly to austerity than lower-debt countries because investors push sovereign yields to prohibitive levels or refuse to lend to them entirely. Alternatively, the link between the fiscal response to a crisis and a country's debt-to-GDP ratio may reflect choices by the country or international organizations. For example, policymakers' ideas may lead them to tighten fiscal policy after a crisis if the debt ratio is high, but not otherwise. Likewise, the views of international organizations such as the European Union (EU) or the International Monetary Fund (IMF) may be tied to the debt ratio, and may drive fiscal policy after a crisis either indirectly (say, through standing EU rules) or directly (through bailout conditionality).

We investigate this issue using both statistical and narrative evidence for thirty Organisation for Economic Co-Operation and Development (OECD) countries for the period since 1980. Our finding is that both market access and policymakers' choices played important roles in the fiscal response to crises over the past 40 years, but choices were somewhat more central. 
A crucial input into our analysis is the indicator of financial distress derived from narrative documents for 24 OECD countries described in Romer and Romer (2017). We extend the indicator through 2017 and incorporate the six additional countries that entered the OECD between 1973 and 2000. We thereby increase the number of observations covered by our measure by more than 20 percent, and the number where our measure shows positive levels of distress by 50 percent. In addition, the inclusion of countries such as Mexico, South Korea, and Hungary allows us to see if less advanced economies fare differently following crises than more mature ones. Extending the series through 2017 enables a much more complete analysis of the aftermath of the global financial crisis than was possible in our previous study (which ended in 2012). For the most part, we find that the extended series yields results similar to those in our previous paper. The average aftermath of a crisis remains negative, highly persistent, and of moderate severity. Contrary to what one might expect, the aftermath of crises is somewhat less severe on average in less advanced economies. Consistent with our previous study, we also find that there is tremendous variation in the aftermaths of crises. Indeed, if anything, including a wider range of countries and more years following the 2008 global financial crisis makes the variation even starker.

To document the importance of fiscal space for the aftermath of crises and the fiscal response, we run panel regressions of output and the high-employment surplus at various horizons after time $t$ on financial distress at $t$, including an interaction between distress and prior debt-to-GDP ratio. The interaction term is consistently highly significant and of the expected sign: high-debt countries have larger output losses following a crisis and undertake fiscal contraction rather than expansion. The extensive literature on the impact of tax changes and government spending on output suggests there is a likely causal relationship between these two developments. Likewise, focusing on the 22 episodes of high financial distress in our sample confirms a strong correlation between the size of the fiscal expansion following a crisis and the prior debt-to-GDP ratio. 
The possibility that the debt ratio matters for the fiscal response to crises because it affects sovereign market access (or because it proxies for market access) can be investigated empirically. Interest rates on government debt, sovereign CDS spreads, and credit-agency ratings are all direct indicators of market access. Likewise, being subject to an IMF or other bailout program likely reflects severe problems with obtaining sovereign funding in private markets. If a country's debt-to-GDP ratio affects the fiscal response to a crisis through market constraints, including such direct measures of market access (interacted with financial distress) in the panel regressions should greatly weaken or eliminate the predictive power of debt for the fiscal response. It does not. While some of the direct measures of market access do seem to affect the fiscal response to a crisis, the effects are generally moderate and only marginally significant. The interaction effect with the debt ratio, on the other hand, remains significant and quantitatively important when the direct measures of market access are included. That is, countries with little fiscal space as measured by their debt-to-GDP ratio undertake less fiscal expansion following a crisis than their lower-debt counterparts, even controlling for the interest rates on their debt and other obvious indicators of market access. This supports the view that choices play an important role in countries' fiscal decisions around crises.

More evidence on the nature and determinants of the fiscal response to crises can be obtained from narrative sources. In particular, we read the Country Reports of the Economist Intelligence Unit (EIU) for the four years following the start of high financial distress in the 22 crisis episodes in our sample. The EIU reports provide a blend of political and policy information that is particularly useful for deducing the motivation for fiscal actions around financial crises. A systematic reading of the reports shows that in some cases, problems with market access unquestionably led to fiscal contraction despite severe post-crisis recessions. This is the case, for example, in Spain and Italy following the 2008 global financial crisis. Sometimes severe market access problems led to an international bailout, where fiscal policy in the affected countries was then driven partly by the views of the rescue organizations; this was the case, for 
example, with Mexico following its crisis in the mid-199os and with Portugal and Greece following the global financial crisis. In many other cases, however, the EIU suggests that the fiscal response to a crisis was driven by the choices of domestic policymakers, and, in the case of some EU countries, by EU rules and ideas. This is always true of post-crisis fiscal expansions, which are inherently discretionary. But choices were also often central to post-crisis austerity, such as in the United Kingdom and Austria following the global financial crisis. Indeed, in roughly half the cases of post-crisis fiscal austerity, the EIU indicates that policymakers' ideas were more important than market access. The EIU Country Reports also provide substantial narrative evidence that both market access and policymaker choices were related to the debt-toGDP ratio.

Our analysis of the role of fiscal space in the aftermath of financial crises is organized as follows. Section I discusses the extension of our narrative measure of financial distress, and revisits our basic findings about the average aftermath of a financial crisis and the variation in outcomes. Section II presents statistical results on the role of the debt-to-GDP ratio in explaining the variation in the aftermath of crises. Section III discusses quantitative evidence on whether the debt-to-GDP ratio matters for the fiscal response to crises because it works through or proxies for market access. Section IV provides narrative evidence on the determinants of the fiscal response following a financial crisis. Finally, Section V discusses our conclusions and the potential implications of our findings for economic policy.

Our study builds on several lines of work. First, it is obviously related to the large, but differently focused, literature on the aftermath of financial crises (for example, Bordo et al. 2001; Reinhart and Rogoff 2009; Romer and Romer 2017; and Baron, Verner, and Xiong 2018). Second, Bohn (1998), Mendoza and Ostry (2008), Ghosh et al. (2013), and others investigate how the conduct of fiscal policy varies with the debt-to-GDP ratio. These papers, however, do not address either how the debt ratio affects the policy response to financial crises or the mechanisms through which the debt ratio affects the conduct of policy. Third, work defining and 
measuring fiscal space (for example, Ghosh et al. 2013 and Kose et al. 2017) is also somewhat relevant to the issues we study. Relatedly, Obstfeld (2013), Elmendorf (2016), and other observers argue that having greater fiscal space can be very valuable in the event of a financial crisis. Our analysis lends strong support to that view.

Our work is clearly also related to the voluminous literature on the output effects of fiscal policy (see Ramey 2016 for a recent survey). The subset of this literature that examines whether fiscal multipliers are larger when the debt-to-GDP ratio is lower (for example, Perotti 1999 and Ilzetzki, Mendoza, and Végh 2013) is closer to the issues we address. However, our finding that the fiscal policy response to financial crises is expansionary at low debt ratios and contractionary at high debt ratios means that the mechanism through which debt affects outcomes in our analysis is different than in those papers.

Finally, the two papers most closely related to our contribution are those by Jordà, Schularick, and Taylor (2016) and Romer and Romer (2018). Both find that the aftermaths of financial crises are far worse in countries with high levels of government debt, and Romer and Romer (2018) find that a likely mechanism behind this link is that the policy response is far more contractionary in high-debt countries. ${ }^{1}$ One contribution of this paper is to extend and amplify these findings. But our main focus, which these papers do not address, is on the reasons for the dependence of the policy response on the level of debt.

\section{Preliminaries}

In order to analyze the aftermath of financial crises, one needs a reliable indicator of when crises occurred in various countries. We use the scaled index of financial distress in OECD countries derived from narrative records described in Romer and Romer (2017). For this paper,

\footnotetext{
${ }^{1}$ Bernardini and Forni (2018) extend this analysis to consider both the level of government debt and its rate of change. They find that when both variables are unusually high prior to a recession that is associated with a financial crisis, the recession is unusually severe and real per capita government spending falls rather than rises. They also show that reliance on IMF credit rises more than usual in such cases, which is suggestive of problems with market access.
} 
we extend the index through 2017 and incorporate six additional countries. This section describes the extension and briefly discusses its impact on some of our previous results.

\section{A. Extending the Measure of Financial Distress}

Our measure of financial distress has three defining characteristics. One is that it is derived from contemporaneous narrative sources. In particular, it is based on the $O E C D$ Economic Outlook, a semiannual review of economic and financial conditions in each OECD country. Since the Economic Outlook is available beginning in 1967, our series on financial distress also begins then. There are two observations per year (corresponding to the two issues of the Economic Outlook), dated approximately June and December.

Second, we take as our definition of financial distress Bernanke's (1983) concept of a rise in the cost of credit intermediation: something makes it more costly for financial institutions to supply credit at a given level of the safe interest rate. It could be an increased external cost of funds due to a widespread loss of confidence; increased costs of monitoring borrowers; or an increased internal cost of funds because of rising loan defaults.

Third, we scale financial distress along a continuum. This reflects the reality that, like most things, financial distress is not a o-1 variable. To do this, we define our measure from o (no distress) to 15 (extreme crisis; widespread chaos and paralysis in the financial system). Values of 7 and above roughly correspond to what the IMF and other chronologies would identify as a systemic financial crisis (Laeven and Valencia 2014). In our analysis, we therefore often pay particular attention to episodes where distress reached 7 or more.

To construct our measure, we specify detailed criteria for translating OECD analysts' words into our numerical scale. Since the OECD does not typically talk in terms of the cost of credit intermediation, this involves looking for sensible proxies in the narrative accounts. Does the Economic Outlook discuss funding difficulties for banks, a breakdown in intermediation, or creditworthy borrowers having difficulty getting loans? Does it describe the problems as 
relatively minor (or perhaps affecting just a small sector of the economy), or severe and widespread? Does it believe that troubles in the banking system are just a risk to the forecast, or central to the outlook? In Romer and Romer (2017, online Appendix A), we describe the criteria for different levels of distress in detail, and provide a summary of the reasoning (and the related quotations from the OECD Economic Outlook) for the observations we scale greater than zero.

Our original index covered the period 1967 to 2012. We also limited our analysis to the 24 countries in the OECD as of 1973. For this paper, we continue the narrative analysis through 2017. We also add the six countries that entered the OECD between 1973 and 2000: the Czech Republic, Hungary, Korea, Mexico, Poland, and the Slovak Republic.

We use the same criteria and approach as we did for the original study. The one difference is that previously we used key word searches (for terms such as crisis or bank) to narrow down the number of country entries we needed to read word for word. Because most countries were still recovering from the global financial crisis between 2012 and 2017, we found it simpler to just read every entry in this period. Likewise, for the added countries, we felt it prudent to read all of their entries in the Economic Outlook because some (particularly the former communist countries) only gradually developed the market-based financial systems that fit into our classification system. For these countries, we do not define our measure of financial distress until the descriptions in the Economic Outlook make clear that the financial system was largely privatized, and that credit availability was therefore mainly determined by market forces. ${ }^{2}$

Table 1 shows the non-zero values of our measure of financial distress for all 30 countries for the period 2013:1 to 2017:2. It also shows all of the non-zero values for the six added countries for all years that information is available. Online Appendix A contains our reasoning for all of the observations added to the sample that we classify as having a positive level of

${ }^{2}$ The starting dates for our measure for these countries are 2003:2 for the Czech Republic (which joined the OECD in December 1995 and first appeared in the 1996:2 issue of the Economic Outlook); 1998:1 for Hungary (May 1996 and 1996:1); 1998:1 for Poland (November 1996 and 1996:2); and 2003:2 for the Slovak Republic (December 2000 and 2000:2). For Korea and Mexico, we define our measure starting when they first appeared in the Economic Outlook (1996:2 for Korea and 1994:1 for Mexico). Online Appendix A discusses the narrative evidence for the appropriate start date for the added countries. 
financial distress. The inclusion of five more years and six additional countries increases the number of observations covered by our measure by 21 percent. However, because there was almost no financial distress in the first two decades of our sample, the amount of distress covered by the measure increases by much more: the number of observations where our measure is strictly positive rises by 50 percent.

Figure 1 shows the expanded measure of financial distress for the 30 countries for $1980-$ 2017, which is the period we focus on in this paper. Panel (a) shows the measure from the start of the period through 2005, when financial distress never affected more than a few countries simultaneously. Panel (b) shows the series for 2006 through the end of the sample, when every country in our sample experienced at least some distress. Relative to our previous sample, there are now two additional episodes of high distress in the 1990s, one in Mexico and one in South Korea. Expanding the sample of countries and going through 2017 also provides a more complete picture of the global financial crisis. Panel (b) of the figure shows that there is tremendous variation in how quickly financial distress faded following 2008. Some countries where the crisis was initially very severe, such as the United States and the United Kingdom, were largely free of distress within a few years. On the other hand, Greece, Ireland, Italy, and Portugal still had some financial distress at the end of 2017. Furthermore, while all of the added countries experienced some distress following 2008, only Hungary experienced distress of 7 or above on our scale (a lower-level moderate crisis).

\section{B. The Average Aftermath of Financial Crises}

Since we have expanded the sample substantially, a useful first step is to see if using the new sample alters our original findings on the average aftermath of financial crises. To investigate the average aftermath, we estimate the following Jordà local projection panel regression:

$$
y_{j, t+h}=\alpha_{j}^{h}+\gamma_{t}^{h}+\beta^{h} F_{j, t}+\sum_{k=1}^{4} \varphi_{k}^{h} F_{j, t-k}+\sum_{k=1}^{4} \theta_{k}^{h} y_{j, t-k}+e_{j, t}^{h},
$$


where the $j$ subscripts index countries, the $t$ subscripts index time, and the $h$ subscripts and superscripts denote the horizon (half-years after time $t$ ). $y_{j, t+h}$ is the logarithm of real GDP in country $j$ at time $t+h . F_{j, t}$ is the financial distress variable for country $j$ at time $t$. The $\alpha$ 's are country fixed effects and the $\gamma$ 's are time fixed effects. We include four lags of both output and distress to account for the usual dynamics of these series.

We estimate (1) separately for horizons o to 10 (that is, up through five years after time $t$ ). The sequence of $\beta^{h}$ 's from these eleven regressions provides a nonparametric estimate of the impulse response function of output to an innovation in financial distress of one step. To get a sense of the aftermath of a "crisis," we multiply the point estimates by 7 , which is the number on our scale corresponding to the start of the "moderate crisis" category. Importantly, the specification includes as part of the average aftermath of distress any contemporaneous relationship between output and distress. Because distress is almost surely at least somewhat endogenous, the estimated impulse response function should thus be viewed as an upper bound of any causal effect of distress on economic activity. ${ }^{3}$ The GDP data are from the OECD. ${ }^{4}$ For consistency with our subsequent empirical work, which uses fiscal data that only begin in 1980, we restrict all of the data used in the estimation to the period 1980-2017.

Panel (a) of Figure 2 shows the estimated impulse response function (along with the twostandard-error confidence bands) using our full set of 30 OECD countries. The figure also shows the results for our original sample of 24 countries. For the full sample of countries, the

3 Romer and Romer (2017) provide an extensive discussion of causation and timing. We find that excluding the contemporaneous relationship between output and financial distress reduces the negative aftermath of crisis by nearly half. This suggests that endogeneity issues are indeed important, and that the true causal impact of financial distress is substantially smaller than the aftermath as estimated in equation (1). Unfortunately, our narrative source is not adequate for identifying genuinely exogenous episodes of financial distress or determining if such episodes even exist in the postwar period.

4 https://stats.oecd.org, downloaded 11/11/2018. The data are from the Quarterly National Accounts Dataset, series VPVOBARSA. GDP data are missing for a few countries in certain years. Because the financial distress variable is semiannual (corresponding to June and December), we convert the GDP data to semiannual as well (using the observations for the second and fourth quarters of each year). Ireland's GDP jumped more than 20 percent in 2015Q1, due largely to the relocation of many companies' intellectual property to Ireland. Because this is such an extreme observation and is unrelated to the normal determinants of output movements, we do not use Irish data after 2014Q4. 
aftermath of a realization of financial distress of a 7 on our scale is a substantial and persistent decline in real GDP. The peak fall in output following a crisis is a decline of just over $4 \%$, and is highly significant $(t=-4.1) .5$

This estimated aftermath is noticeably less severe than we found in Romer and Romer (2017), which was a decline of $6.0 \% .^{6}$ There are three changes in the estimation relative to the previous paper: a larger sample of countries; a different time period (the original time period was 1967-2012); and revisions to the GDP data. Figure 2a shows that considering only the original sample of 24 countries (but for the 1980-2017 time period) results in a decline in GDP following a crisis of $5.2 \%(t=-3.7)$. Thus, the new sample of countries is an important source of the difference between the new estimates and the original ones.

Because the added countries are at the lower end of the spectrum of per capita GDP, it is useful to consider where there are systematic differences in the aftermath of financial crises between richer and poorer countries. Since Greece is an influential observation in whatever sample it is in, it is natural to use it as the dividing line between richer and poorer countries, and to leave it out of either sample. To classify countries, we therefore compare their per capita GDP in 1992 (the first year for which there is annual data on GDP per capita for all thirty countries) to that of Greece.7 Eight countries had a lower GDP per capita than Greece: the Czech Republic, Hungary, Korea, Mexico, Poland, Portugal, the Slovak Republic, and Turkey.

Panel (b) of Figure 2 shows the estimated impulse response functions for richer and

5 Throughout, we report results based on heteroskedasticity-corrected standard errors, which are generally considerably larger than the conventional standard errors from our regressions. We have also examined various ways of correcting the standard errors for serial correlation (Newey-West and HansenHodrick standard errors and clustering by country), as well as clustering by time period. However, because of the inclusion of lags in our regressions, we are focusing on responses to innovations in our variables (in this case, financial distress), which are by construction roughly serially uncorrelated. As a result, one would not expect serial correlation of the residuals to cause important bias in the standard errors. And indeed, the various alternatives do not change the standard errors systematically relative to the heteroskedasticity-corrected ones.

${ }^{6}$ As in Romer and Romer (2017), if we exclude the contemporaneous relationship between output and financial distress in the estimated aftermath, the average aftermath of a crisis is substantially less severe than the baseline estimates. Using the expanded sample considered in this paper, the peak fall in output is just over $2 \%(t=-1.8)$.

7 We use GDP per head (current dollars) from the OECD (https://stats.oecd.org, downloaded 1/4/19). 
poorer countries. Both types of countries have a smaller negative aftermath of crises than the full sample, consistent with the notion that Greece's terrible downturn following the global financial crisis pulls down the average aftermath in the full sample noticeably. ${ }^{8}$ The point estimates for the two types of countries, however, are quite different. The aftermath of crises is more negative and more persistent in richer countries than in poorer ones. Indeed, for poorer countries, the negative aftermath is completely undone within five years of the crisis, whereas for richer countries it is not undone at all. Not surprisingly, given the smaller sample, the twostandard-error bands are very wide for the poorer country sample. Nevertheless, the finding that the negative aftermath of crises appears milder in less advanced countries goes against the common view that crises are more devastating in developing economies.

\section{Variation in Aftermaths}

The variation in aftermaths following a crisis between richer and poorer countries is consistent with the finding in Romer and Romer (2017) that there is, in general, substantial variation in aftermaths across crisis episodes. One way to show this variation is to focus on the 22 episodes of high financial distress (which we define as a reading of 7 or greater on our scale of o to 15) in our sample. We consider forecasts of real GDP in each episode based on the estimates of equation (1). In forming the forecasts, we use the realization of the distress variable up through the half-year that it reaches 7 or higher, and actual GDP up through one half-year before that occurs. We then calculate forecast residuals as actual GDP minus the forecast, so negative residuals correspond to actual GDP being lower than the forecast.

Because we include actual distress up through the start of the forecast, the forecasts take into account that these are all crisis episodes. As a result, the forecast errors are approximately

8 While it does not make sense to ignore the evidence from Greece's experience following the global financial crisis entirely, the fall in its output was so extreme that it natural to wonder if Greece could be driving our results. We have therefore re-estimated all of our key equations excluding Greece from the sample. The general pattern is that dropping Greece weakens the results somewhat, but does not change them qualitatively. Perhaps the most interesting exception is that in some of the regressions in Section III, excluding Greece actually slightly strengthens the relationship between direct measures of market access and the fiscal policy response to financial distress. 
mean zero across episodes. Nevertheless, there is substantial variation in the errors across the episodes. ${ }^{9}$ This variation is the result of differences both in how financial distress itself evolves in each episode, and in how GDP responds to a given level of distress.

Figure 3 shows the forecast errors in the various episodes. We divide them into the cases with very small negative or positive forecast errors and those with substantial negative forecast errors. Even within these two groups, there is a wide range of outcomes. Among the episodes of relatively small or positive forecast errors shown in panel (a), there are cases like Sweden following its 1993 crisis, where the forecast errors are small and negative in the immediate aftermath, but small and positive thereafter. On the other hand, Mexico (following its 1996 crisis), Norway (following its 1991 crisis), and Finland (following its 1993 crisis) all experienced actual growth much higher than the forecast during almost all of the five years following the start of high distress.

There is even greater variation in aftermaths among the episodes of substantial negative forecast errors shown in panel (b) of Figure 3. Greece following its crisis in 2009:1 experienced GDP declines far worse and more persistent than those predicted using equation (1). Likewise, Spain, Portugal, and Italy (following the global financial crisis) and Japan (following its 1997 crisis) experienced severe and persistent negative forecast errors. Two of the poorer countries in this group (Turkey following its 2001 crisis and Hungary following its 2009 crisis) show another interesting pattern. There is a short-run drop in output greater than the forecast (in the case of Turkey, dramatically greater), but then substantial recovery. Indeed, after its catastrophic initial decline, Turkey experienced growth almost equally dramatically above the forecast.

\section{THE IMPORTANCE OF FISCAL SPACE}

The evidence in the preceding section shows that while the aftermath of financial crises is in general quite negative, there is tremendous variation in the severity and persistence of the

9 In this exercise, South Korea is excluded. Its crisis in 1997 occurred just a year after South Korea entered the OECD. As a result, it lacks the four lags of the distress variable needed to construct the forecast. 
output declines following high financial distress. We turn now to the role that fiscal space plays in explaining this variation. The analysis in this section largely extends some of the findings in Romer and Romer (2018) using our larger number of countries and longer time period. Sections III and IV consider the issue of why space matters.

\section{A. Definition of Fiscal Space}

We think of fiscal space as the room a country has to use fiscal policy to stimulate the economy or to undertake a bailout and recapitalization of its financial sector. For our analysis, we define fiscal space as the negative of the ratio of gross government debt to GDP. Thus, it is a continuous measure, with fiscal space declining linearly with the debt-to-GDP ratio.

There are obviously many other ways to define fiscal space. For example, in Romer and Romer (2018), we consider using net debt in place of gross debt, and investigate replacing the linear specification with more complicated threshold-type formulations.$^{10}$ Later in this section, we consider whether the prior budget surplus might be an added component of fiscal space. And, in Section III, we explore whether more direct indicators of sovereign market access dominate the gross debt-to-GDP ratio in determining the post-crisis behavior of fiscal policy. But, a country's gross debt load is a fundamental and intuitive way to conceptualize fiscal space.

A virtue of the (negative of the) debt-to-GDP ratio as the measure of fiscal space is that it is determined in large part by past policy decisions and more long-run features of a country's policymaking process. It captures the fact that some countries (like Greece and Italy) perennially run deficits, while others (like South Korea and Germany) typically pursue balanced budgets. It obviously also responds somewhat to movements in output and fiscal policy around financial crises, but it is typically slower-moving and less cyclically-sensitive than indicators like the budget surplus or interest rates. To further strengthen the exogeneity of the debt-to-GDP ratio to policy decisions around crises, in the regressions that follow we always use the ratio at the

\footnotetext{
${ }^{10}$ We find that these variations have little effect on our estimates of the role of fiscal space, and so do not repeat them in this study.
} 
end of the previous calendar year. ${ }^{11}$

Fiscal data are generally not available on a comparable basis for a wide range of countries before 1980. As a result, our analysis focuses on the period 1980-2017. Data on gross government debt for our sample of countries for most of the period starting in 1980 are available from the IMF World Economic Outlook (WEO) database. ${ }^{12}$ When values going all the way back to 1980 are not available from the IMF, we extend the series back using data from the OECD when possible. ${ }^{13}$ The resulting debt series covers 95 percent of the observations since 1980 for which our measure of financial distress is available.

\section{B. Fiscal Space and the Response of GDP to Financial Distress}

To see if fiscal space explains some of the variation in the aftermath of financial crises, we augment equation (1) to include an interaction term between financial distress and the negative of the debt-to-GDP ratio at the end of the previous year. The coefficients on this interaction term measure how the response of output to distress varies with fiscal space. In addition to the interaction term, we also include (the negative of) the debt ratio alone, again as of the end of the previous year. Thus, we estimate:

$$
\begin{gathered}
y_{j, t+h}=\alpha_{j}^{h}+\gamma_{t}^{h}+\vartheta^{h} S_{j, t}+\beta^{h} F_{j, t}+\delta^{h}\left(F_{j, t} \cdot S_{j, t}\right) \\
+\sum_{k=1}^{4} \rho_{k}^{h} S_{j, t-k}+\sum_{k=1}^{4} \varphi_{k}^{h} F_{j, t-k}+\sum_{k=1}^{4} \omega_{k}^{h}\left(F_{j, t-k} \cdot S_{j, t-k}\right)+\sum_{k=1}^{4} \theta_{k}^{h} y_{j, t-k}+e_{j, t}^{h},
\end{gathered}
$$

where $S_{j, t}$ is our measure of fiscal space in country $j$ in half-year $t$, and all other variables are as before. We again estimate the relationship for the horizons $h=0$ to 10 .

\footnotetext{
${ }^{11}$ The reason for using the debt-to-GDP ratio at the end of the previous year is that the debt-to-GDP ratio data are annual, end-of-year values. Thus we use the debt ratio at the end period $t-1$ when period $t$ corresponds to the first half of the year, and the ratio at the end of period $t-2$ when period $t$ corresponds to the second half of the year.

${ }_{12}$ We use the data from the October 2018 edition of the database, https://www.imf.org/external/pubs/ft/weo/2018/o2/weodata/index.aspx, downloaded 11/11/2018. 13 The OECD data are available from https://stats.oecd.org/, downloaded 11/11/2018. For a few countries, gross debt data for early years of the sample are available in earlier published editions of the $O E C D$ Economic Outlook, but not from the OECD website. In such cases, we use those data (specifically, data from the December 2002 and December 1996 editions of the Economic Outlook). We join the series using splices in levels, working backward in time through the various sources.
} 
Figure 4a shows the estimated coefficient on the interaction term $\left(\delta^{h}\right)$ at the various horizons, together with the two-standard-error bands. To make it easier to interpret the coefficients, we multiply them by a realization of the interaction term of twice the standard deviation of the gross debt-to-GDP ratio in our sample (which is roughly 35 percentage points), times 7. The factor of 7 accounts for the fact that we are interested in the impact of a fairly substantial rise in financial distress (a crisis of some sort). Thus the reported numbers can be interpreted as how the behavior of output following a financial crisis varies with a two-standard deviation increase in fiscal space.

The figure shows that the scaled coefficient on the interaction term is positive at all horizons and statistically significant after horizon 1 (with a maximum $t$-statistic over 3 ). The fact that the coefficients are positive means that the fall in GDP following a crisis is smaller when the negative of the debt-to-GDP ratio is less negative-that is, when there is more fiscal space.

Figure $4 \mathrm{~b}$ presents another way of visualizing the implications of the estimates for the importance of fiscal space. It shows the impulse response function of GDP based on equation (2) to an innovation in financial distress of 7 including both the direct effect of distress (the $\beta^{h}$ s) and the interaction effect (the $\delta^{h}$ 's) for two cases: when the debt-to-GDP ratio is one standard deviation above the sample mean ("less fiscal space"), and when it is one standard deviation below the sample mean ("more fiscal space"). These correspond to debt ratios of roughly 25 and 95 percent.

Figure $4 \mathrm{~b}$ shows that the aftermath of a financial crisis is dramatically different in the two cases. GDP typically falls about 7 percent following a realization of 7 on our scale of financial distress when the debt-to-GDP ratio is one standard deviation above the mean, but by less than 1 percent when the debt ratio is one standard deviation below the mean. While these two cases represent a sizeable difference in the debt ratio, the difference is by no means extreme. And, because space is assumed to decline linearly with the debt-to-GDP ratio, a smaller or larger difference would imply a proportionally smaller or larger estimated difference in the aftermath 
of a crisis.

The two cases presented in panel (b) explain the logic in the construction of panel (a) of multiplying the estimated interaction term by twice the sample standard deviation of the debt ratio, and then by 7. By doing this, we show precisely the difference in the impulse response functions of output to a financial crisis (defined as an innovation of 7 in our measure) between the cases of more and less fiscal space. That is, panel (a) shows the difference between the two impulse responses functions presented in panel (b), together with the two-standard-error bands.

\section{Fiscal Space and the Response of Fiscal Policy to Financial Distress}

The most obvious mechanism by which fiscal space could affect the aftermath of crises is by enabling or limiting fiscal stimulus and financial rescue. It is therefore natural to examine how the behavior of fiscal policy following crises varies with fiscal space.

To do this, we run interaction regressions like those for GDP, but using a measure of the change in the high-employment surplus as the dependent variable. Official estimates of the high-employment surplus are available on a consistent basis for a large number of countries in our sample only for relatively recent years. For this reason, we consider an approximation. For each horizon $(h)$ that we consider, we use as the left-hand side variable the change in the actual budget surplus (as a share of GDP) from $t-1$ to $t+h$, minus the percent change in real GDP times an estimate of the cyclical sensitivity of the surplus to GDP. That is, we estimate

$$
\left(B_{j, t+h}-B_{j, t-1}\right)-\tau \cdot\left(y_{j, t+h}-y_{j, t-1}\right)=\alpha_{j}^{h}+\gamma_{t}^{h}+\vartheta^{h} S_{j, t}+\beta^{h} F_{j, t}+\delta^{h}\left(F_{j, t} \cdot S_{j, t}\right)
$$

$$
+\sum_{k=1}^{4} \rho_{k}^{h} S_{j, t-k}+\sum_{k=1}^{4} \varphi_{k}^{h} F_{j, t-k}+\sum_{k=1}^{4} \omega_{k}^{h}\left(F_{j, t-k} \cdot S_{j, t-k}\right)+\sum_{k=1}^{4} \theta_{k}^{h}\left(\Delta B_{j, t-k}-\tau \cdot \Delta y_{j, t-k}\right)+e_{j, t}^{h},
$$

where $B_{j, t}$ is the budget surplus as a share of GDP in country $j$ in period $t$, and $\tau$ is the assumed sensitivity of the budget surplus to real activity. We estimate (3) for horizons $h=0$ to 10 .

This specification omits the growth of potential output. That is, it leaves out a $\tau \cdot\left(\bar{y}_{j, t+h}-\right.$ $\left.\bar{y}_{j, t-1}\right)$ term in the calculation of the change in the high-employment surplus, where $\bar{y}$ is potential output. If trend growth in each country is constant over our sample period, however, 
that term will be captured by the country fixed effects (the $\alpha_{j}^{h}$ 's). Thus, this method of estimating the change in the high-employment surplus makes sense as long as trend or potential growth for each country does not change greatly over our sample period. Based on the evidence in Girouard and André (2005), a reasonable estimate of $\tau$ for OECD countries is 0.4. Finally, note that since we consider the change in the high-employment surplus over progressively longer horizons, the estimates from (3) inherently show how the cumulative response of the high-employment surplus depends on financial distress and its interaction with fiscal space. ${ }^{14}$

We obtain data on the budget surplus from the same sources as our data on the debt-toGDP ratio. Specifically, the data are from the IMF WEO database when available, supplemented with data from the OECD when those go back further. ${ }^{15}$ The resulting series covers 97 percent of the observations since 1980 for which our measure of financial distress is available.

The results are shown in Figure 5. Panel (a) shows the estimates of the $\delta^{h}$ 's, the coefficients on the interaction term. We again multiply the estimates by 7 and by two times the standard deviation of the debt-to-GDP ratio to aid interpretation. The estimates are negative and highly statistically significant. The fact that the estimates are negative means that countries with lower debt ratios (and so with more fiscal space) respond to financial distress with lower (or more negative) high-employment surpluses. That is, they run more expansionary fiscal policy.

Panel (b) shows the implications of the estimates for the behavior of the high-employment surplus following an innovation of 7 in the new measure of financial distress including both the direct impact of distress and the interaction term. We again consider the cases where the debt-

14 We also examine the effects of allowing $\tau$ to vary across countries using the estimates from Girouard and André (2005, Table 9). Because Girouard and André do not report $\tau$ 's for Mexico and Turkey, we are forced to drop these two countries from our sample. In all cases, the results are extremely similar to our baseline ones for the same sample, although they are typically very slightly stronger.

15 All data were downloaded 11/11/2018, and the data from earlier published versions of the $O E C D$ Economic Outlook are again from the December 2002 and December 1996 editions. For the IMF data, we use the series "General government net lending/borrowing," and for the Economic Outlook, we use the series "Financial balance." We again join the various series using splices in levels, working backward in time through the sources. One small difference from our series for the debt-to-GDP ratio is that we do not use any current OECD data from https://stats.oecd.org/. 
to-GDP ratio is one standard deviation below its mean ("more fiscal space") and where it is one standard deviation above the mean ("less fiscal space"). The figure shows just how important the interaction with fiscal space is. A country facing high financial distress with a debt-to-GDP ratio one standard deviation below the mean cuts its high-employment surplus by 2 to 3 percent of GDP; a country facing high distress with a debt ratio one standard deviation above the mean runs contractionary fiscal policy, with its high-employment surplus rising by 3 percent of GDP.

Given that both GDP and the high-employment surplus following crises vary strongly with the prior debt-to-GDP ratio, it is natural to think that there is a link between the two. A large literature finds that changes in taxes and government spending have powerful effects on real output (for example, Fisher and Peters 2010; Romer and Romer 2010; Ramey 2011; and Guajardo, Leigh, and Pescatori 2014). ${ }^{16}$ Thus, it is highly likely that output declines following crises are larger when a country faces a crisis with high debt because low-debt countries use fiscal policy aggressively to mitigate the impact of the crisis and rescue the financial system, while high-debt countries pursue contractionary fiscal policy.

\section{The Role of the Prior Budget Surplus}

Another variable that may affect a country's ability or willingness to use expansionary fiscal policy in response to financial distress is the level of its budget surplus before the distress occurs. For a given degree of fiscal expansion, the resulting deficit will be larger when the prior surplus is smaller. To the extent a larger deficit increases difficulties with market access or makes policymakers want to pursue less expansionary policy, a smaller prior surplus could therefore lead to a less expansionary response to distress.

\footnotetext{
${ }^{16}$ Another large literature uses cross-section data to investigate the impact of changes in government spending on output and employment (for example, Nakamura and Steinsson 2014, Chodorow-Reich et al. 2010, and Suárez Serrato and Wingender 2016). These cross-section studies typically find a fiscal multiplier of around 1.5. Chodorow-Reich (forthcoming) argues that the cross-section multiplier is an approximate lower bound on the aggregate multiplier for cases where monetary policy does not respond to fiscal policy (which applies to many of the crises in our sample).
} 
To investigate this issue, we estimate variants of equation (3) using the surplus as a share of GDP in the previous year in place of, or in addition to, the (negative of the) previous year's debt-to-GDP ratio. ${ }^{17}$ The results show a strong relationship between the prior surplus and the fiscal policy response to financial distress. When we use the prior surplus in place of the (negative) debt ratio, it is highly significant and quantitatively important. The $t$-statistic on the interaction term between distress and the previous year's surplus ranges from 2.5 to 3.7 (with the exception of horizon $\mathrm{o}$, when it is 1.8), and the point estimates indicate that an improvement of two standard deviations in the prior surplus (roughly 9 percentage points) is associated with a more expansionary response of the high-employment surplus to an innovation of 7 in distress that is smaller than what we find for a two-standard-deviation improvement in the prior debt ratio, but still large-2 to 3 percent of GDP.

When we include both measures, the point estimates on both are quantitatively large, and both are statistically significant. The point estimates suggest that the prior debt ratio is moderately more important quantitatively than the prior surplus; however, the prior surplus is somewhat more statistically significant. The null hypothesis that neither variable is related to the fiscal response to distress is overwhelmingly rejected, with $p$ values less than 0.001 at most horizons. Thus, bringing the prior surplus into the analysis strengthens the finding that there is a powerful relationship between a country's fiscal situation and its fiscal response to financial distress.

At the same time, we are reluctant to place too much weight on the findings involving the prior budget surplus. As discussed above, the debt ratio is determined largely by long-term forces. The prior surplus, in contrast, is heavily influenced by recent policy decisions. One concrete concern is that if policymakers have information about current or prospective financial distress before the distress is reflected in our measure, they may pursue fiscal expansion, and so

${ }_{17}$ When we use the prior surplus in place of the prior debt-to-GDP ratio, we replace the negative of the debt ratio in the prior year $(S)$ with the surplus-to-GDP ratio in the prior year whenever it appears in (3). When we use it in addition to the debt ratio, we add the corresponding variable using the prior surplus-toGDP ratio whenever a variable using the prior debt-to-GDP ratio appears in (3). 
run large deficits, before our measure of distress rises. If so, the finding that a smaller prior surplus is associated with a less expansionary response to distress could reflect not a causal impact of the prior surplus, but merely the fact that countries that act before our measure of distress rises pursue less additional expansion when the increase in our measure occurs. Because of the potential difficulties with interpretations of correlations involving the prior surplus, in the remainder of the paper we continue to focus on just the prior debt ratio. ${ }^{18}$

\section{E. Looking at Episodes of High Distress}

One way to get a sense of the sources of the baseline fiscal space regression results and to have more confidence that they reflect genuine patterns in the data is look at the behavior of debt, the high-employment surplus, and financial distress in the episodes of high distress in our sample. Specifically, we look at the 22 cases where distress reached 7 or more. ${ }^{19}$

Figure 6 shows two cases where the overall patterns fit straightforwardly with the regression results concerning the relationship between fiscal space and the fiscal policy response to distress. The first, Italy in the global financial crisis (panel a), is one where a high-debt country swung strongly to fiscal contraction following a crisis. The second, Norway in the early 1990 (panel b), is a clear example of the opposite pattern: in this case, a country with low debt ran highly expansionary policy following a crisis.

The two cases in Figure 6 are ones where debt and fiscal policy both behave relatively consistently throughout the episode. Perhaps more telling are some of the cases where debt and

\footnotetext{
18 For completeness, we have examined the effects of using the prior surplus either in place of or in addition to the prior debt ratio in all of the empirical exercises reported in the paper. Throughout, the results are qualitatively similar to what we find here. The prior surplus enters in ways that are statistically and quantitatively significant; when both variables are included, the statistical significance of the debt ratio is reduced somewhat, but it remains marginally to very significant, and it has a quantitatively more important role than the prior surplus; and the null hypothesis that neither variable enters is overwhelmingly rejected.

19 To form estimates of the change in the high-employment surplus, we need an estimate of trend growth by country; that is, we need an estimate of the $\tau \cdot \Delta \bar{y}$ term that we are able to omit in estimating equation (3). We use each country's average growth over the full sample period 1980:1-2017:2 as our estimate of the growth rate of potential output in the country. For countries where we do not have GDP data for the full period, we use the average growth rate over the period for which we have data.
} 
fiscal policy evolved over the course of the episode. Two such cases are shown in Figure 7. Ireland (panel a) began its 2009 crisis with a low debt-to-GDP ratio, and it initially responded to high distress by undertaking extreme spending measures to stabilize its financial system. However, as its debt ratio rose and distress continued, Ireland swung strongly to fiscal contraction. The other case, Portugal in the 2008 crisis (panel b), shows a similar (though less extreme) pattern. Because the regressions always consider the recent (but prior) level of the debt ratio, cases where distress continued and fiscal policy swung toward contraction as debt rose fit the regression finding that the policy response to distress is more contractionary when debt is higher.

The cases shown in Figures 6 and 7 help ground the regression results. They show that the estimates are consistent with the behavior of debt and the high-employment surplus in several key crisis episodes. But, obviously, not every episode cleanly matches the regression findings. For example, Korea following its 1997 crisis had ample fiscal space as measured by its debt-toGDP ratio, but nevertheless pursued austerity. And, the United States following its crisis in 2007 is an example of a country with somewhat high debt that nevertheless pursued aggressive fiscal stimulus and financial rescue. Such nonconforming cases are reflected in the standard errors of the regression estimates.

\section{STATISTICAL EVIDENCE ON WHY FISCAL SPACE MATTERS FOR THE POLICY RESPONSE}

The previous section shows that the fiscal policy response to financial distress varies dramatically with a country's prior debt-to-GDP ratio. Countries with low debt-to-GDP ratios on the eve of financial distress expand aggressively, while countries with high debt-to-GDP ratios tighten sharply. The obvious question is why.

\section{A. Possible Explanations}

One possibility is that the link between fiscal policy after crises and the debt-to-GDP ratio 
reflects variation in sovereign market access. Perhaps investors in government bonds are sensitive to a country's fiscal space. In this case, countries with a higher debt-to-GDP ratio may experience larger rises in interest rates following financial distress, and so be less able or willing to engage in fiscal expansion. Indeed, in extreme cases, market access may be so constrained that higher-debt countries may find themselves forced to undertake extreme austerity because they are unable to borrow. Lower-debt countries, on the other hand, may have better market access and so be able to run very expansionary policy.

The broad alternative explanation for the link between the fiscal response to a crisis and fiscal space involves policymakers' choices. Perhaps policymakers have views about the desirability of fiscal expansion or austerity that vary with the debt-to-GDP ratio. For example, policymakers may believe that financial rescue and countercyclical stimulus are appropriate when the debt ratio is low, but not when it is high. Likewise, they may believe that post-crisis austerity is called for when the debt load is heavy, but not when it is light. As a result, a higherdebt country might choose to expand little or pursue austerity following a financial crisis, while a lower-debt country may choose to expand aggressively, even if neither country faces pressure from markets.

The policymakers making such choices are not necessarily those within the country. For example, countries in the European Union (or wishing to join the EU or the euro zone) agree to certain standing rules about debt and deficit levels. Thus, the fiscal response of such countries to a financial crisis may vary with their debt-to-GDP ratio because of the ideas and rules of the EU. Countries with a higher debt-to-GDP ratio may find themselves pressured by the EU to conduct austerity following a crisis, while those with a lower debt ratio remain free to conduct financial rescue and countercyclical stimulus.

The fiscal conditionality imposed by the IMF and other international organizations as part of a bailout reflects a sort of hybrid between the market access and policymaker choice explanations. Countries typically only turn to the IMF when there is an extreme lack of market 
access. Thus being subject to IMF conditionality is in a fundamental sense an indicator of severe market constraints. If market access depends on fiscal space, then being subject to IMF conditionality could be thought of as the mechanism by which fiscal space affects the fiscal response to financial distress. However, the nature of the bailout conditionality, such as the severity of the required austerity and the speed with which the IMF seeks to return countries to private borrowing, depends on the ideas of IMF policymakers about appropriate fiscal policy, and those may also be affected by countries' fiscal space. In the extreme, a country that is forced to go to the IMF for reasons unrelated to its debt load could nevertheless have its fiscal response be related to its debt-to-GDP ratio purely because of IMF ideas.

The main goal of this section and the next is to obtain evidence about the relative roles of sovereign market access and policymakers' choices in accounting for the link between the fiscal response to financial distress and the debt-to-GDP ratio. This section considers statistical evidence. As we describe below, there are various direct measures of market access, such as sovereign bond rates and credit ratings. If market access is key, these variables should be better predictors of the fiscal policy response to a crisis than the debt-to-GDP ratio. Indeed, if market access is crucial and the direct measures are good indicators, the debt ratio would have little or no predictive power once these measures are included. On the other hand, if market access is not crucial and policymakers emphasize the debt ratio in making choices about fiscal policy, then including direct measures of market access should have little impact on the predictive power of the debt ratio for the policy response.

\section{B. Measures of Sovereign Market Access}

We consider four relatively direct measures of sovereign market access. The first is the spread on credit default swaps (CDS) for government debt. Concretely, we use the spread on 5year senior government debt. ${ }^{20}$ Since a CDS contract is insurance against default, in principle

20 The data are originally from Credit Market Analysis (CMA) and Thomson Reuters, downloaded from 
the CDS spread should be an excellent measure of the premium a country must pay to borrow because of fears about its solvency. Thus, it should be a good measure of market access.

In practice, however, CDS spreads have several drawbacks. First, the contracts did not exist at all until the 1990s, and our data for most countries do not begin until 2004. Second, the markets are often thin, and in some cases inoperative. For example, the reported CDS spread for Greece shows literally no change from February 2012 to March 2017. Third, the observation for Greece over this period (14,904.36 basis points) is so extreme that using the raw data would effectively amount to just including a dummy variable for Greece in this period. We therefore drop Greece from regressions including the CDS spread. Finally, the CDS spread on a bond of one specific maturity is an imperfect measure of a government's access to bond markets at other maturities, and CDS spreads omit some important risks lenders face, notably restructuring designed to not trigger CDS contracts and the inflating away of debt. ${ }^{21}$

Our second measure is simpler: long-term interest rates on sovereign debt. In particular, we use the nominal rate on long-term (roughly 10-year) government bonds. ${ }^{22}$ These data have the advantages of being available for a large fraction of our sample, coming from relatively thick

DATASTREAM 12/3/2018. We use the average of the daily observations for the last month of the halfyear to construct our semiannual observations. We link the CMA and Thompson Reuters data by splicing in the last half-year where there is overlap. The contracts are denominated either in euros or U.S. dollars, with the exception of those for Japan, which are in yen.

${ }^{21}$ We make two adjustments to the CDS data. First, in the handful of cases where the splicing implies a small negative spread, we set the spread to zero. Second, although data for most of the countries in our sample begin in 2004, for some countries whose debt was regarded as extremely safe, they do not begin until later. In order to mitigate somewhat the loss of observations from using the CDS data, we set the spread for these countries from 2004 until it is first available to zero. The result is a series that covers 29 of the 30 countries in our sample for 2004-2017. (The missing country is Luxembourg, which did not issue long-term debt over this period.) Using the data without these adjustments yields very similar results.

${ }_{22}$ We begin with IMF data on long-term government bond rates (downloaded from International Financial Statistics, data.imf.org/IFS , 12/2/2018). When those are not available, we use the long-term rates from the OECD (downloaded from Federal Reserve Economic Data, https://fred.stlouisfed.org/, 12/2/2018), splicing the two series (in levels) at the point of overlap. The data are generally for bonds with maturities of approximately ten years. For Mexico until 2001 and Turkey, however, the data are for bonds with maturities of roughly two years. We use the observations for the last month of the half-year. For the handful of cases where the data for the last month of the half-year are not available, we use the observation for the previous month. Finally, although the IMF reports data for Luxembourg, the documentation notes that Luxembourg stopped issuing long-term debt in January 1985 and that the reported data are for private debt (IMF 2018). We therefore treat the observations for Luxembourg starting in 1985 as missing. 
markets, and, as with CDS spreads, reflecting market-based assessments of the riskiness of countries' debt. However, they are affected by factors other than riskiness, notably short-run monetary policy and trend inflation. And, as with the CDS spread, the long-term interest rate on a 10-year bond is an imperfect measure of the premium a government must pay at other maturities. ${ }^{23}$

Our third measure is Standard \& Poor's (S\&P) sovereign bond ratings. We convert S\&P's letter grades into numerical scores by making the step between each grade of equal size, with higher letter grades corresponding to higher scores. ${ }^{24}$ This is arguably our most preferred measure of market access: it is continuous, available for most of our sample, and reflects professional assessments of a wide range of information about the riskiness of countries' debt. At the same time, S\&P's assessments are necessarily imperfect, market access may not be linear in S\&P's letter grades, and no single measure can capture market access over the full range of maturities of a country's bonds.

Our final measure of market access is a dummy variable for whether a country is subject to an IMF stand-by arrangement or extended fund facility. ${ }^{25}$ As discussed above, countries generally turn to the IMF only when they face severe difficulties in borrowing in private markets. Thus, being under an IMF program is a strong indicator of very limited market access. At the same time, however, this variable is also an indicator of being subject to IMF

${ }^{23}$ We also consider the spread between a country's long-term rate and the German rate (or the lower of the German and U.S. rates), rather than the long-term rate. The relationship between the spread and the policy response is slightly stronger than that between the long-term rate and the policy response when we do not include the debt-to-GDP ratio, but slightly weaker when we include the debt ratio. Using the spread rather than the long-term rate has no discernible effect on the relationship between the debt ratio and the policy response.

24 The data are from https://www.capitaliq.com/CIQDotNet/CreditResearch/RenderArticle.aspx?articleId=2094846\&SctArtI $\mathrm{d}=460711 \&$ from=CM\&nsl code=LIME\&sourceObjectId=10686180\&sourceRevId=1\&fee ind=N\&exp da $\underline{\text { te}}=20281001-19: 20: 54$, downloaded 11/18/2018. We use the rating as of the end of the half-year. We assign a value of 30 to a AAA rating, 27 to AA, and so on down to 3 to $\mathrm{D}$ (although the lowest rating for the countries in our sample is CC, to which our scale assigns a 9). We add a point when the rating is accompanied by a plus and subtract a point when it is accompanied by a minus.

25 Information on IMF programs is from https://www.imf.org/external/np/fin/tad/extarr1.aspx, downloaded 1/2/2019. Our measure is a dummy variable for whether a country was subject to a program at the end of the half-year. 
policymakers' views. As a result, the interpretation of any estimated impact is inherently complicated.

With all four indicators of market access, we specify the variable so that a larger value corresponds to more access. Specifically, we multiply the CDS spread, the sovereign bond rate, and the IMF dummy (but not the credit rating variable) by negative one.

\section{Does Sovereign Market Access Affect the Fiscal Response to a Crisis?}

We begin by considering the predictive power of the various direct measures of sovereign market access for the response of the high-employment surplus to financial distress. These regressions can show if better market access appears to be associated with a more aggressive fiscal response to a crisis.

For this exercise, we estimate regressions analogous to equation (3) with the debt ratio replaced by one of the measures of market access:

$$
\left(B_{j, t+h}-B_{j, t-1}\right)-\tau \cdot\left(y_{j, t+h}-y_{j, t-1}\right)=\alpha_{j}^{h}+\gamma_{t}^{h}+\eta^{h} M_{j, t}+\beta^{h} F_{j, t}+\lambda^{h}\left(F_{j, t} \cdot M_{j, t}\right)
$$

$$
+\sum_{k=1}^{4} \rho_{k}^{h} M_{j, t-k}+\sum_{k=1}^{4} \varphi_{k}^{h} F_{j, t-k}+\sum_{k=1}^{4} \omega_{k}^{h}\left(F_{j, t-k} \cdot M_{j, t-k}\right)+\sum_{k=1}^{4} \theta_{k}^{h}\left(\Delta B_{j, t-k}-\tau \cdot \Delta y_{j, t-k}\right)+e_{j, t}^{h} .
$$

Here $M_{j, t}$ is a measure of sovereign market access and the other variables are as before. Our main interest is in the sequence of estimates of $\lambda^{h}$, which show how the fiscal response to distress varies with market access.

Throughout, the measure of market access in period $t$ is based on information as of the end of the previous half-year. Thus, for example, we use information on the long-term interest rate or the S\&P rating at the end of the half-year before period $t$ in constructing $M_{j, t}$. We are therefore asking whether the fiscal policy response to financial distress varies with the degree of market access the country faced prior to distress. This timing puts the measures of market access on roughly the same footing as the debt-to-GDP ratio in the regressions in the previous 
section. ${ }^{26}$

One concern is that previous market access may be a less good predictor of current market access than the previous debt ratio is of the current ratio. This could make the estimated interaction effect for the market access variables less comparable to that for the debt ratio in the previous section. As a simple test for this, we regress each market access variable on country and time fixed effects, and four half-yearly lags of itself. The sum of the coefficients on the lag terms range from 0.76 for the IMF dummy to 0.94 for the S\&P rating. The comparable sum of the lag terms for the debt ratio is $0.96 .{ }^{27}$ The sum of the lag coefficients is overwhelmingly significant in all cases. These findings suggest there is some validity to this concern, but it may not cause large incomparabilities. Moreover, we are hesitant to adjust the timing to use the more nearly contemporaneous measures of market access because of endogeneity concerns. Without the lag in timing, it is impossible to distinguish between market access in times of distress affecting the fiscal response to a crisis, and the fiscal response to a crisis affecting the contemporaneous state of market access.

Including the Measures of Market Access One at a Time. Figure 8 shows the results of estimating equation (4) including the measures of market access one at a time. There are four panels; each corresponds to a different measure of market access. Paralleling panel (a) of Figure 5, each panel shows the sequence of estimates of the interaction term, scaled for ease of interpretation. As discussed above, we specify the measures of market access in such a way that a negative coefficient on the interaction term means that better market access is associated with a smaller value of the change in the high-employment surplus, and hence with a more expansionary fiscal policy response. We also always multiply the coefficients on the interaction term by 7 so that we are focusing on substantial financial distress. For the IMF dummy, we make

${ }^{26}$ Because the market access measures are high frequency, while the debt ratio is annual, the market access variables are slightly less lagged than the debt variable. For the second observation of each year, the debt variable corresponds to the end of the previous calendar year, whereas the market access variables correspond to the end of June.

27 Because there are not true semiannual observations for the debt data (we simply repeat the value for both half-years), we run the regression for the debt-to-GDP ratio at an annual frequency. 
no further adjustment, so what is shown is simply the difference in the policy response between a country not subject to an IMF program and a country subject to one. For the other three measures (the CDS spread, the long-term interest rate, and the S\&P rating), we also multiply the estimated coefficients on the interaction term by twice the standard deviation of the measure, which is analogous to our treatment of the debt-to-GDP ratio in Figure 5. In short, each panel shows the estimated difference in the response of the high-employment surplus as a percent of GDP to an innovation in financial distress of 7 in a country with better market access versus a country with worse market access.

Panel (a) of the figure shows that there is basically no correlation between a country's CDS spread and its fiscal response to financial distress. The estimated impact of having a spread that is two standard deviations lower (roughly 230 basis points) on the response of policy to an innovation of 7 in financial distress is of irregular sign, quantitatively small, and never close to statistically significant. The confidence intervals include moderately negative and moderately positive values, but do not include large values.

For the other three measures, better market access is associated with a more expansionary fiscal response to financial distress. The results are strongest for the IMF program dummy (panel d). The point estimates imply that the response of the high-employment surplus in a country that is not subject to an IMF program to an innovation in distress of 7 is more expansionary by up to 6 percent of GDP. The null hypothesis that the responses do not differ between a country not subject to a program and a country subject to one is decisively rejected, with a maximum $t$-statistic over 4 .

The results for the other two measures are not as overwhelming, but still strong. For the interest rate on long-term government debt (panel b), having a sovereign yield two standard deviations lower (8.6 percentage points) is associated with a substantially more expansionary fiscal policy response to a financial crisis (often exceeding 2 percent of GDP), but with wide 
confidence intervals and a maximum $t$-statistic of only 2.2. ${ }^{28} \mathrm{~A}$ two-standard-deviation improvement in a country's S\&P rating (roughly 8 points on our numerical scale, for example from $\mathrm{B}$ to $\mathrm{A}-$ ) is associated with a more expansionary policy response of similar size (2 percent of GDP or more) and is highly statistically significant at short horizons, with a maximum $t$ statistic of $3 \cdot 3$.

Including Multiple Measures of Market Access. Each of the direct measures of market access captures slightly different features of a country's ability to borrow. Moreover, each measure has unique strengths and limitations. Thus, it is sensible to see if the measures considered jointly have more substantial predictive power for the fiscal response to a financial crisis than each considered separately. To do this, we expand equation (4) to include the level and interaction with distress (as well as the appropriate lags) of three measures of market access: the long-term government bond rate, the S\&P sovereign rating, and the dummy for being under an IMF program. We exclude the CDS spread because its inclusion limits the sample period so severely.

For each horizon of the impulse response function, we consider the point estimate and statistical significance of the sum of the interaction of each measure of market access with financial distress times twice its standard deviation. As in Figure 8, we also multiply the weighted sum of the interaction terms by 7 . Thus it shows how the response to an innovation of 7 in financial distress changes with an improvement of two standard deviations in all three measures of market access.

Figure 9 shows the results. The point estimates of the weighted sum of the interaction terms are negative for the first $2^{1 / 2}$ years following crisis. This suggests that countries with better market access engage in more expansionary fiscal policy following a crisis than countries with

${ }^{28}$ The value we use for the standard deviation of the long-term interest rate excludes Turkey. Our data for the long-term rate include only a handful of values for Turkey, but not enough consecutive data points for any observations from Turkey to enter the regression. In addition, the values of the long rate for Turkey are so extreme (generally close to 100 percent) that including them would almost double the overall standard deviation. 
worse market access. The point estimates after $2^{1 / 2}$ years are very close to zero (until year 5 , when they fluctuate substantially). Perhaps more important than the point estimates is the statistical significance of the weighted sum. The standard errors of the sum of the interaction effects are substantial, particularly at longer horizons. As a result, the impact of market access on the fiscal response to a crisis is statistically significant at only one horizon (horizon 2). That the three measures of market access considered jointly have a less precisely estimated impact on the fiscal response to a crisis than two of the measures considered individually (the S\&P rating and the IMF dummy) reflects both changes in the sample caused by including all three measures and interactions between the various measures.

\section{Does the Debt Ratio Affect the Fiscal Response through Market Access?}

The previous regressions show whether direct measures of sovereign market access predict the fiscal policy response to financial crises. They do not, however, answer the question raised by the results in Section II, which is why the debt-to-GDP ratio appears to matter. This issue can be addressed by testing whether including direct measures of market access drives out the predictive power of the debt ratio.

Including the Measures of Market Access One at a Time. To do this we estimate regressions along the lines of equations (3) and (4), but now including both (the negative of) the debt ratio and a measure of market access:

$$
\begin{gathered}
\left(B_{j, t+h}-B_{j, t-1}\right)-\tau \cdot\left(y_{j, t+h}-y_{j, t-1}\right)=\alpha_{j}^{h}+\gamma_{t}^{h}+\vartheta^{h} S_{j, t}+\eta^{h} M_{j, t}+\beta^{h} F_{j, t}+\delta^{h}\left(F_{j, t} \cdot S_{j, t}\right) \\
+\lambda^{h}\left(F_{j, t} \cdot M_{j, t}\right)+\sum_{k=1}^{4} \rho_{k}^{h} S_{j, t-k}+\sum_{k=1}^{4} \rho_{k}^{h} M_{j, t-k}+\sum_{k=1}^{4} \varphi_{k}^{h} F_{j, t-k}+\sum_{k=1}^{4} \omega_{k}^{h}\left(F_{j, t-k} \cdot S_{j, t-k}\right) \\
+\sum_{k=1}^{4} \mu_{k}^{h}\left(F_{j, t-k} \cdot M_{j, t-k}\right)+\sum_{k=1}^{4} \theta_{k}^{h}\left(\Delta B_{j, t-k}-\tau \cdot \Delta y_{j, t-k}\right)+e_{j, t}^{h} .
\end{gathered}
$$

Thus, this regression includes both the interaction between financial distress and the debt ratio and the interaction between distress and a direct measure of market access. We first include the measures of market access one at a time.

Figure 10 shows the results. Each panel considers a different measure of market access. 
The panels show two sets of estimates of differences between the fiscal policy responses to an innovation of 7 in financial distress: between countries with better and worse market access (with the differences measured in the same way as in Figure 8), and between countries with smaller and larger debt-to-GDP ratios (with the difference equal to two standard deviations, or roughly 70 percentage points, as in Figure 5a). Since the key question is whether including the measures of market access weakens the predictive power of the debt ratio, we also include the point estimate of the scaled interaction term for the debt ratio from the specification that excludes the market access measures (equation (3)). The sample period used to estimate the specification excluding the market access measure is adjusted to match that for the specification including the market access measure in each case. Thus the two estimates of the interaction effect for the debt ratio given in a panel differ only because of the inclusion of the market access measure. The differences in the sample period also explain why the estimate of the debt interaction excluding market access differs across the panels and from the baseline results given in Figure 5a. To keep the figures readable, we do not show the interaction effect for the market access variable from the specification excluding the debt ratio (equation (4)), but we do discuss how this effect changes as well.

The basic message of the figure is that including the direct measures of sovereign market access attenuates the estimated effect of the debt-to-GDP ratio on the fiscal response to a crisis by at most a moderate amount (and usually just a very small amount), while including the debt ratio often has a large impact on the estimated effects of the measures of market access. Panel (a) considers the case where the CDS spread is used to measure market access. The estimate of the interaction effect for the debt ratio from the expanded specification is shown in dark blue; that from the specification excluding the measure of market access (but using the same very short sample for which the CDS spread is available) is shown in light blue. Including the interaction with the CDS spread reduces the interaction with the debt ratio a moderate amount at very short horizons, but increases it at longer horizons. That is, fiscal policy following a 
financial crisis is somewhat less responsive to the debt ratio when the CDS spread is included, but only at short horizons. And even in this smaller sample, the impact of the debt ratio on the fiscal response at short and medium horizons is large, though only marginally significant. In contrast, including the debt ratio makes the results for the CDS spread even weaker than before. The estimates are generally wrong-signed, and at long horizons (with, as just noted, small sample sizes), marginally significant.

Panel (b) shows that including the interest rate on long-term government debt has essentially no effect on the estimated impact of the debt-to-GDP ratio on the fiscal policy response to financial distress. It also shows that including the debt ratio noticeably weakens the predictive power of the long-term rate for the policy response. The estimated impact remains negative at short horizons, but is now at most weakly significant; and it is now positive, though statistically insignificant, at longer horizons. Panel (c) shows that when the S\&P rating is included, the estimated impact of the debt ratio on the fiscal response to a crisis weakens by about 20 percent, but remains large and often statistically significant. It is also shows that including the debt ratio has a larger effect on the estimated impact of the S\&P rating. Its estimated effect remains consistently negative, but is somewhat smaller than before and statistically significant only at horizon 2.

Finally, panel (d) shows the results for the dummy for being subject to an IMF program. The inclusion of a measure of market access again reduces the estimates of the effect of the debtto-GDP ratio on the response to financial distress by about 20 percent, though they are still large and often significant. And again, the inclusion of the debt ratio has a larger effect on the estimates of the effects of the measure of market access. At short horizons, the estimated effect continues to be large and overwhelmingly significant, though it is noticeably weaker than before. But at medium horizons, the effects move from very large and highly significant to moderate and not significant; and at long horizons, they become positive, though not significant.

Including Multiple Measures of Market Access. We again consider a more 
extreme test. We allow the fiscal policy response to financial distress to depend on the debt-toGDP ratio and on three measures of sovereign market access: the long-term government bond rate, the S\&P rating, and the IMF dummy. That is, we expand equation (5) to include three measures of market access (and their interactions with financial distress), rather than just one. (We again do not include the CDS spread, on the grounds that doing so would entail a very large reduction in the sample size and that the previous results find essentially no effect of the spread.)

Figure 11 shows two scaled estimates of the interaction effect with financial distress for various horizons: that for the debt ratio and that for the weighted sum of the three direct measures of market access (calculated as in Figure 9). As in Figure 10, we also show the interaction effect for the debt ratio from equation (3) (where the measures of market access are excluded), but for the same sample period as those from expanded specification.

The figure shows that the estimated sensitivity of the fiscal response to a crisis to the debtto-GDP ratio is only mildly affected by the simultaneous inclusion of multiple direct measures of market access. The impact remains large and generally statistically significant; the inclusion of the multiple measures of market access reduces the point estimates by about $20 \%$ relative to our baseline estimates. Thus, the debt-to-GDP ratio appears to matter substantially for the fiscal response to a crisis, even when one takes into account the behavior of the three direct measures of market access. As in Figure 9, the weighted sum of the interaction terms for the three measures of market access is initially negative, but it is only marginally significant at one horizon (horizon 2). The weighted sum of the interaction effects then turns positive, with very large standard errors.

\section{E. Discussion}

The statistical results advance our understanding of the fiscal policy response to financial distress in two ways. First, they provide some evidence that market access matters. There is a 
moderately large, moderately significant, and relatively robust relationship between the rating on a country's sovereign debt and its fiscal policy response to distress; and there is a large, highly significant, and very robust relationship between a country being subject to an IMF program and its short-run fiscal response. Countries with higher-rated debt respond more aggressively to distress, and the immediate response of countries that are subject to an IMF program is far more contractionary than that of countries that are not. In addition, countries respond less aggressively to distress when the interest rate on their long-term debt is higher, and they respond less aggressively at longer horizons when they are subject to an IMF program. However, these relationships are not as consistent as those for the rating and for the immediate impact of being under an IMF program.

Second, we find that including direct measures of sovereign market access does not eliminate the estimated impact of the debt-to-GDP ratio on the fiscal response to financial crises. Indeed, using a range of measures (both singly and in combination) of market access only slightly attenuates the correlation between the debt-to-GDP ratio and the fiscal policy response. This suggests that an important part of the relationship between the debt ratio and the fiscal response to a crisis is working through channels other than market access. The natural alternative is that those other channels involve choices by policymakers.

\section{NARRATIVE EVIDENCE ON THE MOTIVATION FOR FISCAL POLICY FOLLOWING CRISES}

In this section, we turn from statistical to narrative evidence. There are several reasons that the broader, more qualitative evidence provided by narrative sources may be able to provide important additional information about the determinants of the fiscal policy response to financial distress. First, and most obviously, our interest is in the motivations for policy actions. Thus, there is likely to be valuable evidence from policymakers' statements, news accounts, and other descriptions of the policymaking process available to informed contemporary observers. 
Second, all of our direct measures of sovereign market access are imperfect. As a result, the statistical relationship between the measures and the fiscal policy response to financial distress may understate the importance of market access. It is therefore useful to examine whether analysts making more holistic judgments about the drivers of policy decisions perceived a greater role for problems with market access than comes through in our statistical analysis.

Third, and closely related, problems with market access may involve large and complicated nonlinearities that would be extremely difficult to detect statistically. For example, suppose that there is some level of fiscal expansion that would trigger a sudden, sharp rise in interest rate spreads and severe problems with market access, and that this level varies across situations. If policymakers are aware of these limits and careful not to breach them, concerns about possible imminent loss of market access could be driving fiscal policy without showing up in our measures. But such considerations might be apparent to observers monitoring countries' decision-making.

Motivated by these considerations, in this section we seek to provide narrative evidence on the relative importance of market access and policymaker choices in driving fiscal policy actions around crises. We also investigate the degree to which government debt ratios appear to underlie or influence market access and policymaker choices. The narrative analysis focuses on the 22 episodes of high distress in our sample.

\section{A. Source and Approach}

The source that we use for this analysis is the Economist Intelligence Unit's Country Reports. ${ }^{29}$ The EIU is a subscription service providing information on political and economic developments in a wide range of countries. The reports are aimed at investors and other market professionals, and appear to be of reasonably high quality. Each one is around 25 pages, and makes frequent reference to data, legislative debates, and political developments. The service

29 The EIU Country Reports after 1996 are available from EIU.com; those before 1996 are available from the Economist Intelligence Unit Country Reports Archive through ProQuest. Binder (2018) uses the Country Reports as a narrative source to study political pressure on central banks. 
relies, in part, on the reporters and analysts working for the Economist magazine for its information. Because the reports focus particularly on policy actions, we find them to be a plentiful source on the motivations for those actions.

The EIU Country Reports are available quarterly until early 2000, and monthly thereafter. The reports for the first quarter (which came out in early January) and the third quarter (which came out in early July) are roughly comparable in timing to the OECD Economic Outlook, from which we derive our measure of financial distress (the Economic Outlook comes out in December and June). When the reports become monthly, we treat those for January and July as the parallel to the OECD volumes..$^{30}$ Our approach is to read the EIU Reports for a country corresponding in timing to the OECD Economic Outlook starting in the half-year before financial distress reached 7 or above. We read nine issues for each episode of high distress-two a year from one-half year before the crisis to four years after.

We look for what the EIU Reports say about four questions:

1. What is the current and/or prospective stance of fiscal policy?

2. What is the motivation given for the fiscal developments?

3. Does the EIU mention the debt-to-GDP ratio as a concern or as an underlying motivation?

4. Is there anything else of note relevant to fiscal policy actions?

From the answers to question (1), we identify whether fiscal policy at the time was perceived by the EIU to have been on net expansionary or contractionary, and whether the net movement was large or small. The overall direction of fiscal policy is usually stated quite directly. To categorize size, we rely mainly on adjectives. Fiscal moves described with works like "mild," "minor," and "small" are classified as small; those described with words like "enormous," "unprecedented," and "extreme" are classified as large. This scaling is obviously rough. In the tables that summarize the narrative evidence, we therefore note cases that are marginal for a

30 We do this in part for consistency with the early years of the EIU Reports, and in part because, for a transition period, the December and June issues are updates rather than full reports. In addition, there are a few irregularities in which EIU reports we consider. For example, the report for Sweden for 1994Q1 is not available from ProQuest. Similarly, in a few cases in the early 2000s, the January and July issues are updates and the December and June issues are full reports. In such cases, we use a rule of reason and read the obvious alternative report. 
category.

In classifying the motivation given by the EIU for fiscal actions (question 2), we are open to nuance and multiple motivations. For fiscal expansions, we identify three possible motivations:
a. Financial rescue.
b. Countercyclical stimulus.
c. Politics.

The EIU typically says why some fiscal action was taken, not why some other action was not taken. That is, the counterfactual is implicitly or explicitly neutral fiscal policy. As a result, market access is inherently not an explanation for fiscal expansions, and all of the possible motivations correspond to policymaker choices. Actions taken for countercyclical stimulus or financial rescue can be thought of as reflecting policymakers' ideas: policymakers take the actions because they believe the policies will be helpful. "Politics" (category c) refers to fiscal stimulus taken to try to help win an election.

For fiscal contractions we consider five possible motivations:

d. Market access.

e. Conditionality imposed as part of a bailout.

f. Policymaker ideas.

g. European Union fiscal rules.

h. Countercyclical austerity.

"Market access" captures austerity that the EIU identifies as being driven by very high sovereign spreads, inability to borrow, or other problems with private sovereign funding. The final three motivations correspond to policymaker choices. As described above, policymaker ideas and EU rules largely differ in whose ideas are mattering-those of domestic policymakers or EU officials. "Countercyclical austerity" (category h) refers to contractionary fiscal actions taken to prevent overheating, and can again be thought of as a special form of policymaker ideas. Finally, "conditionality" is the hybrid of market access and IMF (or other bailout organization) choices 
discussed above. ${ }^{31}$

Question (3) reflects both information about policymakers' concerns about the debt-toGDP ratio in an episode and the EIU's perspective. We take note of the EIU's assessment on the grounds that when we do not have direct information on policymakers' views, it at least provides the assessment of one contemporary informed observer of whether debt was important. However, we put the main emphasis on the information the EIU provides about policymakers' views. We pay particular attention to whether the EIU believes that the debt-to-GDP ratio is driving the proximate motivation-for example, whether it cites the debt-to-GDP ratio as something that is affecting market access or policymakers' ideas.

Online Appendix B provides our detailed notes and selected quotations for each EIU country report that we read, organized around the four questions discussed above. Table 2 provides the topline summary of what the EIU says about the net direction, size, and motivation for fiscal actions in each of the 22 episodes of high financial distress.

\section{B. Post-Crisis Fiscal Expansions}

Table 3 summarizes the narrative evidence from the EIU on net fiscal expansions following high financial distress. According to the EIU, in almost all of the 22 crisis episodes in our sample there was at least a short period of deliberate net fiscal expansion following the start of high distress. The only exceptions are Mexico (in the mid-1990s) and Hungary (in 2009). In both cases, high financial distress followed extreme exchange rate fluctuations, and the country was already participating in an IMF stabilization program at the time of severe problems in the financial sector. South Korea followed a similar pattern, with very early austerity as part of an IMF program to deal with its 1998 crisis. However, unlike Mexico and Hungary, Korea undertook fiscal expansion after conditions stabilized. The much more typical pattern is for the fiscal expansions to occur early in the post-crisis period.

${ }^{31}$ Not surprisingly, the motivations given in the EIU Country Reports occasionally do not fit into one of the eight categories we identify. In these cases, we note an "other" motivation. 
Panel (a) of Table 3 divides the net fiscal expansions into those that were described by the EIU as small and those described as large. As can be seen, small expansions were more common than large ones. Panel (b) shows the motivations given by the EIU for the net fiscal expansion in each case. As discussed above, the three possible motivations-financial rescue, countercyclical stimulus, and politics-all correspond to policymaker choices. Each line in panel (b) corresponds to an episode, so that it is easy to see multiple motivations by episode.

Financial Rescue (a). One thing that jumps out from Table 3 is that financial rescue is nearly universal. Of the 20 cases of deliberate net fiscal expansion, the EIU identified financial rescue as a motivation in 19 of them. The only case where it was not given as a motivation is the United States following its 1990 crisis; however, in this case there was a bailout of the savings and loan industry that occurred before our narrative source identified substantial financial distress. Even in the two cases where there was no net fiscal expansion (Mexico and Hungary), the EIU reported substantial support for the financial system. This suggests remarkable agreement across policymakers from different countries that financial rescue is valuable and appropriate in times of high financial distress.

There is also an obvious correlation between the EIU's perceived size of the fiscal expansion and financial rescue. All 8 of the countries described as taking large post-crisis fiscal expansions are also described as being strongly motivated by financial rescue. For example, of Finland following its 1993 crisis, the EIU wrote: "parliament approved a motion saying it would grant sufficient funds and authorising the government to use them to secure 'under all circumstances' the continued operation of Finland's banks" (1 $1^{\text {st }}$ quarter 1993, p. 8). Likewise, the EIU discussed that in Iceland following the 2008 crisis, "gross government debt is forecast by the IMF to increase from $29 \%$ at the end of 2007 to $109 \%$ of GDP in 2009, as a result of meeting the obligations of the former three main Icelandic banks now taken into public ownership and the injection of new funds to recapitalise them" (January 2009, p. 9). That the largest fiscal expansions involved very aggressive financial rescue also suggests that policymakers viewed 
such rescues as a valuable use of public funds following a financial crisis.

Countercyclical Stimulus (b). A desire to stimulate aggregate demand and counter the contractionary consequences of a financial crisis is a less frequently cited motivation for post-crisis fiscal expansion. The EIU listed it as a motivation in 14 of the 20 cases of net expansion (and in 4 of those it was only a minor motivation). This could suggest that the idea that fiscal stimulus is helpful and appropriate following a financial crisis was less widely held among policymakers than a belief in the efficacy and appropriateness of financial rescue.

The EIU descriptions provide interesting insight into the interaction between the financial rescue and countercyclical motivations. Some countries appear to have embraced both motivations strongly. For example, the EIU said of Japan following its 1998 crisis both that the "government ... is now focusing on a bail-out of the financial sector" (1 $1^{\text {st }}$ quarter 1998, p. 3), and "in mid-November the government unveiled a new package of proposals designed to stimulate economic recovery" (1 $1^{\text {st }}$ quarter 1999, p. 17). The United States following the 2008 crisis was similarly described as acting with gusto because of both motivations: "Mr Obama has already made it clear that he will do everything to contain the crisis and that he is backing another fiscal stimulus package” (January 2009, p. 4).

Other countries appear to have embraced the financial rescue motivation strongly, but believed that they should do little or no conventional fiscal stimulus. For example, the EIU described the United Kingdom following the 2008 crisis as undertaking "unprecedented moves last year to support the banking sector" (January 2009, p. 4), but only a "£2obn (US\$3obn) fiscal stimulus package (the main element of which is a temporary cut in the rate of value-added tax (VAT) from $17.5 \%$ to $15 \%$ until end-2009)" (January 2009, p. 5). Indeed, at least three countries were described as believing in aggressive financial rescue and conventional fiscal austerity simultaneously (Sweden in the early 1990s, and Iceland and Ireland after the global financial crisis). For example, Ireland is described by the EIU as "taking all possible measures to support the financial system" (July 2009, p. 5), while at nearly the same time "[p]ublic spending 
is being cut as the government attempts to control an exploding budget deficit" (January 2010, p. 8).

Still other countries appear to have been relatively unmotivated by either financial rescue or countercyclical purposes, and therefore undertook only modest net fiscal expansion. This was the case with France and Italy following the 2008 crisis. For example, the EIU described the Italian government as taking "some modest anti-cyclical measures" (January 2009, p. 12), and having "guaranteed deposits up to about $€ 100,000$ and allowed banks to negotiate state help in recapitalisation, although no major Italian bank is at present in urgent need of state support” (January 2009, p. 4).

Politics (c). A final fact evident from panel (b) of Table 3 is that the EIU rarely attributed fiscal expansion following a financial crisis to political motives. One case where it did so was Portugal following the 2008 crisis. The EIU wrote: "The 2009 budget marked a break from the previous fiscal consolidation efforts, partly as a result of the economic slowdown, but also in light of the upcoming general election" (January 2009, p. 4). Even when political expediency was mentioned as a motivation, it was typically identified as a minor factor and was often seen as driving the precise timing of fiscal expansion rather than the overall direction. For example, in the case of Japan following its 1998 crisis, the EIU said: "With the possibility of a difficult lower house election and little sign of the hoped-for self-sustaining recovery in private-sector demand, the government will have little choice but to maintain a broadly accommodating fiscal policy in 2000-01" ( $1^{\text {st }}$ quarter 2000, p. 8). That political considerations were rarely mentioned is perhaps not surprising given that after financial crises there were often more proximate and obvious motivations for the EIU to discuss.

\section{Post-Crisis Austerity}

Table 4 summarizes the narrative evidence from the EIU on deliberate moves to net austerity during crisis episodes. Panel (a) shows that, according to the EIU, in 19 of the 22 
episodes of high financial distress, governments eventually switched to net austerity. Most of these fiscal contractions were described as large, and typically occurred at least a year or two after the start of high distress. The only episodes where the EIU did not describe a deliberate move to net austerity were Japan following its 1998 crisis, and Sweden and Norway following the 2008 crisis.

Panel (b) shows the motivations for austerity given by the EIU in each episode. As discussed above, the motivations reflect a mixture of market access constraints and policymaker choices. Again, each line corresponds to an episode, so that multiple motivations are obvious.

Market Access (d). Problems with sovereign market access were cited as a motivation for fiscal contraction in 14 of the 19 moves to austerity. While in some of these instances market access was a minor motivation or just one of several motivations, in at least half of them the EIU described market access as the primary or overarching motivation for austerity. This finding is somewhat at odds with the empirical evidence in Section III. While the statistical analysis found some role for market access in driving the fiscal response to crises, it was relatively minor and decidedly smaller than that of policymaker choices. Overall, the EIU appeared to rank market access roughly on par with policymaker choices in driving post-crisis austerity.

The EIU identified market access as a motivation for austerity in a wide range of situations. For example, it wrote of Sweden following its 1993 crisis: "The government is aware that the key is to reduce the budget deficit, as only then will it be able to obtain favourable credit conditions and reduce its public debt" ( $3^{\text {rd }}$ quarter 1995 , p. 11). In this case, market access problems sound reasonably minor, and the government was undertaking austerity proactively to reduce interest rates on government bonds. The EIU described a more pressing market access motivation for Italy following the 2008 crisis: "The minister of the economy, Giulio Tremonti, appears determined to keep Italy's public finances under control, fearing that a severe deterioration would lead to a further sharp widening of interest rate spreads on Italy's government debt" (January 2009, p. 4). At the more extreme end of the spectrum is the case of 
Portugal following the 2008 crisis. The EIU wrote: "The Socialist Party (PS) government faces a major challenge to reduce the budget deficit, under severe pressure from financial markets" (July 2010, p. 3).

Bailout Conditionality (e). When market access problems became severe, as they did in Portugal during the global financial crisis, countries were typically forced to turn to the IMF or other international bailout organizations. The EIU identified 8 cases where a country was forced to adopt austerity as a condition for international aid. For example, the EIU said of Portugal in 2011: "The bail-out ... will depend on implementation of a severe fiscal squeeze, in order to reduce the government's budget deficit to below 3\% of GDP and beyond" (July 2011, p. 5). Similarly, the EIU wrote of Ireland: "The government's economic policy will remain focused on implementing the austerity and financial and structural reforms agreed in exchange for access to a €85bn EU/IMF lending facility" (January 2011, p. 3).

As can be seen from Table 4, the cases where market access problems were severe enough to lead to an IMF rescue typically involved large net fiscal contractions. For example, the EIU wrote of Greece: "In May 2010 Greece signed a Memorandum of Understanding (MoU) with representatives of the European Commission, European Central Bank (ECB) and IMF (the 'troika'), which committed it to a draconian programme of fiscal consolidation and economic reform" (July 2011, p. 5). The one exception to this pattern was South Korea following its 1998 crisis. Korea was described by the EIU as following required austerity only for a relatively short time. It is perhaps not a coincidence that the EIU reports also contained frequent mentions of the fact that "South Korea's public finances are sound compared with those of many other OECD countries. Gross government debt stands at around 10\% of GDP” (August 2001, p. 11).

Ideas (f). While the EIU clearly believed that market access problems and bailout conditionality were motivations for post-crisis austerity in a number of cases, it suggested that policymakers' choices also played an important role. The EIU identified domestic policymakers' ideas as a motivation for austerity in 13 of the 19 cases of deliberate post-crisis fiscal contraction. 
In some cases, the EIU was quite explicit about the role of ideas in motivating austerity. For example, according to the EIU, Finland adopted austerity following its 1993 crisis because the "centre-right government" believed it would "reduce unemployment by stimulating the private sector" ( $3^{\text {rd }}$ quarter 1993, p. 9). Later in this episode, the EIU confirmed the role of ideas when it reported that the president "has been quick to reassert that the problem [of high unemployment] cannot be combated by more state borrowing" ( $3^{\text {rd }}$ quarter 1994, p. 15). Likewise, after engaging in both financial rescue and fiscal stimulus in the immediate aftermath of the 2008 crisis, policymakers in Denmark switched to austerity in mid-2010. According to the EIU, the prime minister "used his final New Year address before the next general election to highlight the need for deeper structural reform of the welfare system to prepare Denmark for the future fiscal challenges of population ageing" (January 2011, p. 13).

The EIU's descriptions of the United Kingdom's move to austerity in mid-2010 provide a somewhat more circumstantial case that ideas were a key motivation. The EIU reported that "[t]he chancellor justified the extent of the fiscal squeeze on the grounds that it was needed in order to retain the confidence of the markets." It then went on to say, however, that "[d]espite record issuance, the UK bond market has been one of the strongest in industrialised economies this year" (July 2010, p. 16). The juxtaposition of the stated fear of market access problems and benign actual conditions suggests that ideas about the harms of deficits and high debt were key. The EIU's statement that "the Conservative chancellor of the exchequer, George Osborne, insists that weak economic activity will not deflect the coalition from its aggressive deficit-reduction plans" (July 2011, p. 13) could also suggest an ideological motivation for the austerity.

The case of the United Kingdom makes it clear that even large fiscal contractions following a financial crisis can be motivated by ideas. The EIU said of British policy in 2010: "The scale of fiscal consolidation implied in the budget is immense. Total discretionary tightening of $£ 113 b n$ (US\$170bn) a year is planned by 2014/15 (April-March), compared with current levels, equivalent to $6.5 \%$ of projected GDP" (July 2010, p. 6). Austria is another case where substantial 
austerity was driven by ideas (and EU rules). The EIU repeated described contractionary moves of $2 \%$ of GDP or more despite no issues with market access (see, for example, July 2010, p. 9, and July 2012, p. 4).

Unfortunately, the EIU did not provide much information about the precise ideas that motivated policymakers' choices to adopt austerity. One idea that it sometimes cited was concern about long-run market access. For example, in discussing the switch to austerity in the United States in 2011, it reported, "Although there is no immediate pressure on the government's finances, Washington appears set on tackling the deficit aggressively” (July 2011, p. 4). It also said, "The government faces no funding pressures at present .... However, ... [h]igh debt levels create the risk of an eventual rise in US bond yields that would increase borrowing costs” (p. 6). Another example is provided by Sweden's decision to pursue contraction in terms of conventional fiscal policy after its banking crisis in the early 1990s. In the context of a discussion of falling long-term interest rates, the need to attract capital foreign, and the government's contractionary fiscal policy, the EIU said, “The central government wants to keep up this level of enthusiasm. Luckily, its credit rating is still good and should remain so" (3rd quarter 1993, p. 12). The United Kingdom's shift to austerity in 2010 also appears to largely fit into this category. As described above, the government cited the need to maintain market access as a key motivation for austerity despite exceptionally low long-term interest rates. Indeed, the only potentially imminent issue with market access the EIU reported in this entire episode was a possible downgrade of the United Kingdom's sovereign bond rating from AAA (July 2009, p. 6; January 2010, p. 3). Thus the concerns involving market access appear to have been largely long-term. ${ }^{2}$

Concerns about future market access are related to the idea that a financial crisis can lead

${ }^{32}$ The one piece of evidence in the other direction is that the EIU reported, "The budget's austere tone has reduced near-term market concerns over fiscal sustainability" (July 2010, p. 6). However, since this discussion came soon after the fears of the possible downgrade, and since the EIU also reported that "there is no indication that investors are shunning UK gilts" (p. 16), it appears that the EIU was referring to the potential downgrade, not the possibility of severe loss of market access. 
to a sovereign debt crisis (for example, Reinhart and Rogoff 2009). Following the global financial crisis, two other ideas that received considerable attention are that crossing a specific debt threshold can greatly harm growth (for example, Reinhart and Rogoff 2010), and that austerity can be expansionary, particularly if it focuses on spending cuts (for example, Alesina and Ardagna 2010). However, these ideas barely registered in the EIU Country Reports. The closest the EIU came to discussing a debt threshold came in its analysis of France, where it often mentioned the possibility that debt would reach the 90\% of GDP level emphasized by Reinhart and Rogoff. Its strongest statement was, "With public debt forecast to rise to close to 90\% of GDP by 2012, an additional risk is that France could lose its AAA rating on sovereign debt, which would push up interest costs" (January 2011, p. 8). But this idea did not appear in other episodes. And even in the case of France, the EIU was not explicit that it attached particular importance to the $90 \%$ figure, rather than just using it as a convenient round number to describe the trajectory of France's debt.

Similarly, ideas related to Alesina and Ardagna's work received only a few passing mentions. For example, at one point the EIU attributed the composition of fiscal policy in Ireland, but not its overall direction, to these ideas. In explaining why a budget consolidation was "to be achieved almost exclusively by expenditure reductions," it said, "the government has explicitly acknowledged that international evidence points to spending cuts being a more effective route to consolidation than tax increases" (January 2010, pp. 5-6). Similarly, the EIU implicitly cited this line of work in giving its own views of fiscal policy in the United Kingdom, but it did not attribute this view to policymakers. It said, "The government has been criticised in some quarters for targeting too rapid a pace of deficit reduction at a time of economic uncertainty and minimal funding pressures, but there is no accepted orthodoxy on the impact that fiscal austerity will have on economic activity" (January 2011, p. 7).

Most often, however, the EIU did not provide specific information about the ideas that motivated policymakers' choices to pursue austerity. Instead, it simply reported that 
policymakers viewed high debt or deficits as problems that needed to be addressed. For example, in discussing Norway's shift to austerity in the wake of its banking crisis in the early 1990s, it said, "policymakers are having to concentrate on potential long-term problems. One of these is the budget deficit" (3rd quarter 1994, p. 6). Similarly, in discussing Denmark move to austerity following the global financial crisis, the EIU referred to " $[\mathrm{t}] \mathrm{he}$ need for budgetary consolidation" without explaining the reasons for the need (January 2010, p. 5). And it reported, "the deterioration in the public finances has also made the electorate aware of the long-term costs of sustaining Denmark's welfare benefits” (p. 4). Another example comes from the EIU's discussion of France's turn to austerity in the wake of its crisis in 2008. It said simply that one "legacy of the 2008-09 downturn" is "a need for fiscal tightening," without explaining why (July 2011, p. 8).

European Union Fiscal Rules (g). A motivation for austerity following financial distress also related to ideas involved the fiscal rules set by the EU. As discussed above, such rules can be thought of as reflecting the ideas of EU policymakers. This is especially true given that the EU appears to have had substantial leeway in how aggressively it pressured member countries to conform to the guidelines. There was also a role for domestic policymakers' ideas in how willingly they acceded to EU wishes. This was especially true in cases where countries worked to meet the guidelines out of a desire to qualify for membership.

The EIU mentioned EU fiscal rules as a motivation for fiscal actions in 11 of the 19 cases of post-crisis austerity in our sample. Four of these cases involved countries taking actions in advance of participation in an EU program. The EIU wrote of Sweden in 1995: "The government is bullish about the fiscal outlook. Its EMU [Economic and Monetary Union] convergence plan presented in June includes new savings measures to be introduced, if needed, from 1997 " ( $3^{\text {rd }}$ quarter 1995, p. 1). Finland following its 1993 crisis was also described as undertaking austerity to satisfy EMU criteria ( $3^{\text {rd }}$ quarter 1995 , p. 5). Likewise, both Turkey's and Hungary's postcrisis austerity was partly attributed to desire to join the EU. For example, the EIU said of 
Turkey: "The IMF will provide the extra lending in return for government abidance by a programme of tight fiscal policy backed by privatisation and structural reforms .... This programme had already been set out in the three-year Pre-Accession Economic Programme (PEP) drawn up for the EU on November $30^{\text {th" }}$ (January 2005, p. 19).

The other cases where the EIU mentioned EU rules as a motivation for post-crisis austerity involve existing EU members. For example, it wrote of Austria following the 2008 crisis: "The coalition has agreed in principle with the European Commission in its 2010-13 Stability Programme to act to reduce the government deficit to below 3\% of GDP by 2013" (July 2011, p. 5). Similarly, for France following the global financial crisis, the EIU wrote that "Germany will press for more intrusive budget monitoring of euro area members, which would be likely to stoke further tension with France, given the country's poor fiscal record and habit of flouting the euro area's fiscal rules when these conflict with its domestic priorities" (July 2010, p. 5). This statement makes it clear that EU rules and actions sometimes reflected the ideas of foreign policymakers.

Countercyclical austerity (h). Very rarely, the EIU described countries as undertaking austerity at some point after a crisis for countercyclical purposes. That is, policymakers tightened fiscal policy to prevent the economy from overheating. The most obvious case involved Norway following its crisis in the early 1990s. As can be seen from Figure 3a, Norway grew much more rapidly following its crisis than one would have predicted based on its previous history. The EIU wrote: "as growth accelerates the government will continue to introduce spending cuts in a counter-cyclical fashion," and, "as growth is picking up it finds itself in a position to make the necessary cuts, while at the same time overseeing a reduction, if not the eradication, of the budget deficit" (1 $1^{\text {st }}$ quarter 1995, pp. 5 and 11).

Overall, the EIU's discussion of the motivation for post-crisis austerity paints a mixed picture. The EIU clearly saw an important role for market access problems, often accompanied by an IMF bailout and conditionality, in driving austerity. At the same time, domestic 
policymakers' ideas, often interacting with EU rules and ideas, were also seen as an important factor. Thus, the EIU provides narrative evidence that post-crisis austerity was often at least partly a choice.

\section{Narrative Evidence on the Role of Debt in Driving the Fiscal Response to Crises}

A central finding from our statistical work is that the debt-to-GDP ratio has substantial predictive power for the fiscal policy response to financial distress, and that this is true even controlling for more direct measures of market access. It therefore makes sense to ask what our narrative analysis shows about the link between debt and the fiscal policy response to a crisis.

In examining the EIU Reports for evidence about this issue, we look for cases where the EIU explicitly cited countries' debt as mattering, as opposed to more general comments about influences from countries' fiscal situations. And we focus on cases where the EIU saw debt as affecting the views and behavior of investors, policymakers, and international organizations, rather than ones where it appeared to be just expressing its own concerns. Of course, the EIU probably did not report every instance where debt influenced the policy response. But we take discussion of the role of debt in the Country Reports as an indication that debt was important.

The first finding is that the EIU often described debt as affecting the fiscal policy response to crises. In 18 of our 22 episodes of high distress, the EIU believed that debt had at least some impact on the policy response. 33

In two of those episodes (Norway and Sweden following the 2008 crisis), the EIU saw low debt as an important factor behind fiscal expansion. For example, in explaining Sweden's continued expansionary policy well after the peak of its financial distress, the EIU said: "With

\footnotetext{
33 The four episodes where the EIU did not describe a link are Norway (1991), Mexico, Korea, and Ireland. The EIU's discussion of policy in Norway following its crisis included one reference to the possibility of net debt becoming positive, and of this development having the potential to affect policy ( $3^{\text {rd }}$ quarter 1992 , p. 5). But the EIU did not attribute this view to policymakers or tie it to actual policy. In the cases of Korea and Mexico, the EIU reported severe problems with market access, but did not connect them with the level or trajectory or debt. And in the case of Ireland, the EIU viewed the large deficits arising from its massive financial rescue as an important source of its adoption of austerity, but again did not assign a role to debt.
} 
public debt and the government deficit low, the coalition has been able to introduce some stimulus measures” (January 2012, p. 3).

In the remaining 16 cases, the EIU described high or rising debt as a force fostering fiscal austerity or limiting expansion. The information about the channels through which the EIU described debt as affecting policy in these episodes is summarized in Table 5 . The most common channel was through the views of domestic policymakers. The level or increase of debt was frequently invoked as a reason to limit expansion or switch to contraction, and altering the path of the debt-to-GDP ratio was often an explicit goal of policy. For example, the EIU reported that a contractionary budget in Finland following its 1993 crisis was "intended as part of a drive to ensure that state debt does not rise beyond 70\% of GDP" ( $3^{\text {rd }}$ quarter 1993, p. 4). Similarly, the EIU described how, soon after Austria's 2008 crisis, the vice-chancellor "indicated that the government will begin to unwind its fiscal stimulus measures as it seeks to prepare for austerity measures," and that he "rejected a third stimulus package, claiming that Austria must focus on reining in its rising government deficit and public debt” (January 2010, pp. 5 and 11). In some of the cases, the apparent link between debt and idea-driven policy is more tenuous. For example, in analyzing the U.S. response to its 2007 crisis, the EIU reported: "the rise in federal debt ... is ... a serious concern" (January 2010, p. 6), and, "US public debt has risen sharply in recent years .... Washington appears set on tackling the deficit aggressively” (July 2011, p. 4). But it did not clearly tie these views to specific policy actions.

Table 5 also shows that in a few cases, direct concern about the level of debt had substantial effects through EU fiscal rules. In describing fiscal policy in Finland a few years after its crisis, for example, the EIU said: "Economic policy will be driven by the government's determination to take part in the third stage of Economic and Monetary Union (EMU) .... The most immediate threat to Finland's qualifying for inclusion is its public debt .... Fiscal policy will therefore remain tight" ( $3^{\text {rd }}$ quarter 1995, p. 5). 
Importantly, debt also played a significant role through its influence on market access. In many cases, the link was direct: debt was a source of concern to investors, and so led to problems with market access. For example, the EIU reported that in Italy following the global financial crisis: "The spread of the Greek debt crisis since the end of 2009 forced Italy ... to reduce [its] budget deficits and government debt burdens in order to prevent a further loss of investor confidence" (July 2010, p. 6). As another example, in describing Turkish fiscal policy in the wake of its 2001 crisis, the EIU linked the government's austerity to a desire to avoid a sovereign debt crisis, and linked the possibility of such a crisis to investors' concerns about Turkey's high debt ratio: “A tighter 2003 budget than initially expected [and other factors] ... should be enough for Turkey to avoid a crisis this year. But because of the sheer size of Turkey's government debt (about $85 \%$ of GDP at end-2002), the widening current-account deficit and Turkey's vulnerability to sudden shifts of investor sentiment, the risk of a financial crisis will remain high during the outlook period" (July 2003, p. 9).

In several cases, the EIU discussed loss of market access leading countries to turn to international organizations for help, which then imposed conditionality that put considerable emphasis on the behavior of debt. One example of such conditionality is provided by Portugal following its crisis. The EIU stated: "A bail-out from the joint EU/IMF emergency credit facility will entail strict fiscal consolidation," a key goal of which would be "to stabilise public debt by 2013" (July 2011, pp. 4 and 6). Another example comes from Hungary after its crisis, where the EIU reported: "The [European] Commission and the IMF both called for an exact timetable on Hungary's path towards a state debt ceiling of 50\% of GDP” (July 2011, p. 13).

A final finding, which is not shown in Table 5, concerns the type of fiscal policy that the EIU viewed as being influenced by debt: in every case where the EIU perceived debt as promoting austerity or limiting expansion, it was through its influence on conventional fiscal policy. That is, there were no cases where the EIU reported that government debt limited the extent of financial rescue. The closest was a hypothetical about Italy: "In the event of a collapse 
of the banking sector ..., the Italian state would have less credibility than Germany, France or the UK if it were to intervene in a dramatic way, since public debt is over $100 \%$ of GDP" (January 2009, p. 4). But even in this case, the EIU did not view debt as limiting financial rescue. This reinforces the evidence for near-universal support for rescue in the event of severe financial distress.

The strong evidence from the narrative analysis that debt was often a driver of the fiscal policy response to a crisis is consistent with-and helps explain-the finding from our statistical work that the debt-to-GDP ratio is a powerful predictor of the policy response, even controlling for what are arguably more direct measures of market access. The narrative analysis finds that not just investors, but domestic policymakers, the EU, and the IMF, used the level of debt and its changes as important markers of countries' financial health and an important guide to policy. Thus, it is not surprising that we find that the debt-to-GDP ratio appears to be an important determinant of how countries respond to financial distress, and that it appears to matter even controlling for direct measures of market access.

\section{E. The EIU's Assessments of the Fiscal Response to a Crisis and Data on the Prior Debt Ratio}

Our final exercise is to examine the relationship between the EIU's descriptions of the fiscal response to financial distress and countries' prior debt-to-GDP ratios. Specifically, for each of the various groups of episodes reported in Tables 3,4 , and 5 , we find the average debt ratio across the episodes in the group. In this way, we are blending the narrative evidence on the size and motivations of the fiscal response to crises with actual data on the debt-to-GDP ratio. As in our statistical work, to avoid direct reverse causation from fiscal policy to debt, we use figures for debt as of the end of the year before when the EIU first described a development. 34 If debt is

\footnotetext{
34 Recall that we use the first EIU report of a year largely to gain insight into developments late in the year before. For developments first reported in these reports, we therefore use the debt number from the end of the calendar year two years before that of the report. Thus, for example, for the U.S. financial rescue, which was first reported in the January 2009 report, we use the debt number for 2007. When we report debt numbers for cases where the EIU did not describe a development (such as episodes where the EIU
} 
an important determinant of how fiscal policymakers respond to financial distress, one would expect to see a connection between the prior debt-to-GDP ratio and the EIU's accounts of the nature and determinants of fiscal policy following crises. At the same time, because the number of observations in each category is small and the EIU's general descriptions of fiscal policy are presumably less precise than our data, we do not view this evidence as central to our analysis.

Table 6 presents the results. The patterns go in the directions one would expect, but not overwhelmingly so. Debt was on average slightly lower in situations where the EIU saw the adoption of highly expansionary policy following high financial distress than in cases where it saw a move to only small (or no) expansion; and debt was noticeably higher when the EIU reported the adoption of sharp austerity than when it reported a shift to only mild austerity. 35 The debt ratio was typically 10 to 15 percentage points higher in situations where the EIU first reported a given motivation for austerity than when it first saw a given motivation for expansion; this is what one would expect if debt affects the direction of the policy response. And, consistent with our findings that debt affects the policy response to financial distress through multiple channels, the average debt ratio varied little across cases with different motivations for expansion, or across cases with different motivations for austerity.

The results are stronger when we turn to cases where the EIU reported an impact of debt on policy-perhaps not surprisingly, the EIU perceived debt as having a more contractionary influence on policy when the debt-to-GDP ratio was larger. Most notably, debt was much lower in the cases where the EIU reported that debt fostered expansionary policy, or when it never described an influence of debt, than in the cases where it saw debt contributing to austerity. ${ }^{36}$ And looking across the various channels through which the EIU reported that debt affected austerity, the average debt ratio was relatively high for all of them. It was highest when debt

never saw austerity), we use the figures from the year before distress first reached 7. Finally, because our debt data for Mexico do not begin until 1996, the figures we report do not include Mexico's crisis episode. 35 As an accounting matter, the reason the average debt ratio is quite high for the three countries with no austerity is that one of them (Japan) had very high debt.

${ }^{36}$ The reason the entry for "No role mentioned" is based on three observations rather than four is that as described above, we do not have debt data for Mexico's crisis episode. 
affected austerity through conditionality and market access, and lowest when its effects operated through the ideas of domestic policymakers. Thus, the relationship between the EIU's descriptions of the fiscal policy response to a crisis and the actual debt ratio provides some additional support for the findings that debt affects the policy response to financial distress, and that it does so both via market access and through other mechanisms.

\section{CONCLUSIONS}

Summary. There is compelling evidence that a country's fiscal response to a crisis is correlated with its prior debt-to-GDP ratio. Countries that face a crisis with lower debt pursue more expansionary fiscal policy than countries that face a crisis with higher debt. Indeed, our estimates based on data for 30 OECD countries since 1980 suggest that facing a crisis with a debt ratio one standard deviation below the sample average is associated with a highemployment surplus in the aftermath of a crisis that is roughly 4 percentage points smaller (that is, more expansionary) than facing a crisis with a debt ratio one standard deviation above the average. Moreover, this large difference in the policy response is associated with a large difference in the aftermath: low-debt countries experience much milder downturns following a crisis than high-debt countries.

This paper seeks to understand why the prior debt-to-GDP ratio appears to matter for the fiscal response to crises. We find that including direct measures of sovereign market access, such as long-term government bond rates or sovereign credit ratings, does not eliminate, or even greatly attenuate, the estimated impact of the debt-to-GDP ratio on the high-employment surplus following crises. This strongly suggests that the debt ratio does not matter simply through its impact on current market access or because it is a proxy for market access. Rather, an important part of why it matters appears to be through its impact on policymaker choices.

Narrative evidence from the Economist Intelligence Unit suggests a somewhat larger role for market access in driving the fiscal response to crises than the statistical evidence. This is 
especially true if IMF fiscal conditionality is thought of as an extension of market access problems. But, the evidence from the EIU also indicates that policymakers' choices were often important. In at least half of the cases of post-crisis austerity, the EIU assigned a central role to the ideas of domestic policymakers or European Union fiscal rules. Moreover, the EIU provides evidence that policymakers' choices depend in substantial part on the debt-to-GDP ratio. Thus, it confirms that the debt ratio matters in considerable part through those choices.

Taken together, the statistical and narrative evidence suggests that both sovereign market access and policymakers' choices help account for the observed correlation between a country's debt-to-GDP ratio and the fiscal response to crises. The combined weight of the two types of evidence, however, points to policymakers' choices as somewhat more central.

Possible Policy Implications. There are two directions one might be tempted to go in drawing policy implications from these findings. The first would be to argue that the fact that a high debt-to-GDP ratio is clearly associated with worse post-crisis outcomes is a compelling reason for countries to keep their debt ratio in check if they want to avoid extended periods of poor economic performance. By doing so, a country could reduce the chance that it would face severe market access problems that forced it to respond to a crisis with austerity. It would also mean that domestic policymakers would be less likely to choose counterproductive austerity following a crisis or face pressure from external organizations to do so.

But our finding that the debt ratio matters for the post-crisis fiscal response in substantial part through policymakers' choices suggests a second possibility. Policymakers in countries with good market access could choose not to base post-crisis fiscal policy on the debt ratio. That is, rather than respond to the evidence that debt matters for the fiscal response by reducing debt proactively, policymakers could change their ideas about the desirable fiscal response to a financial crisis when the debt ratio is high. Similarly, the EU could adopt a more flexible set of fiscal rules that allowed member countries to expand aggressively following crises, regardless of debt levels. Even the IMF, which is only called in when market access disappears, could adopt 
less rigid fiscal constraints as a condition for its assistance.

Importantly, since we find that debt matters for the fiscal response to crises through both market access and policymakers' choices, these two possibilities are not mutually exclusive. Countries could work to keep debt low as an insurance policy for future crises and to minimize market risks. But, confronted with high financial distress, domestic policymakers and leaders of international organizations could not let debt loads drive the fiscal response unnecessarily.

Such a combined strategy would obviously involve important dynamic considerations. If high-debt countries did not choose tight fiscal policy following a crisis, it is possible that market access problems would eventually develop. But this possibility does not mean that the status quo of high-debt countries with ample market access choosing austerity following a crisis is necessarily optimal. An alternative is a new policymaker consensus that stresses running responsible fiscal policy in ordinary times, and undertaking aggressive fiscal expansion if at all possible in response to a financial crisis. 
FIGURE 1

Measure of Financial Distress for an Extended Sample of Countries and Time Period

a. $1980-2005$

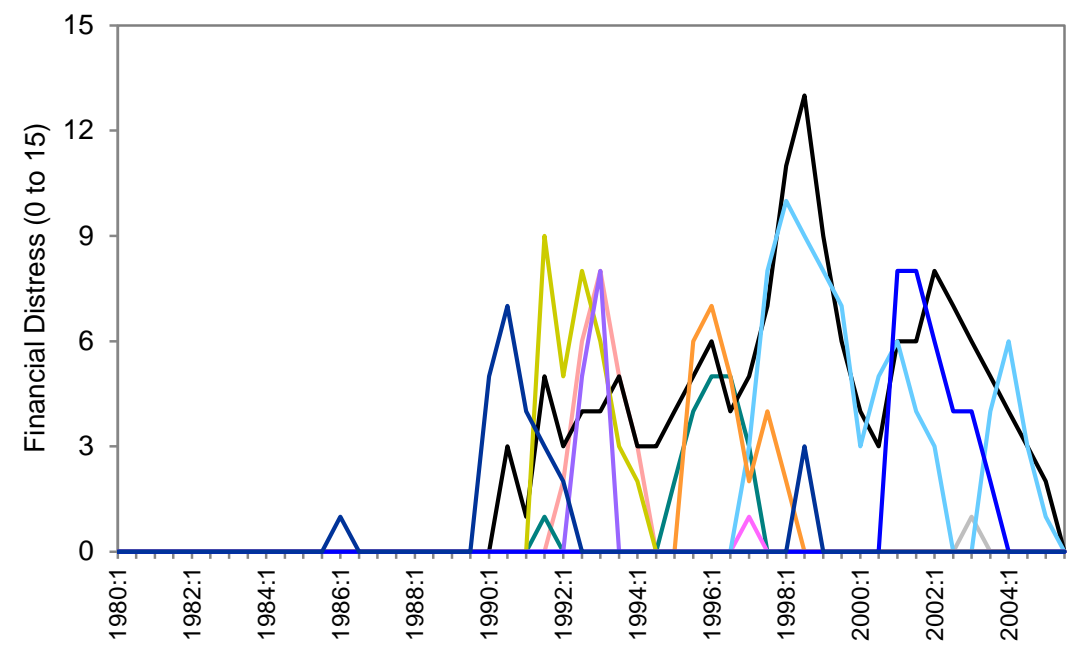

b. $2006-2017$

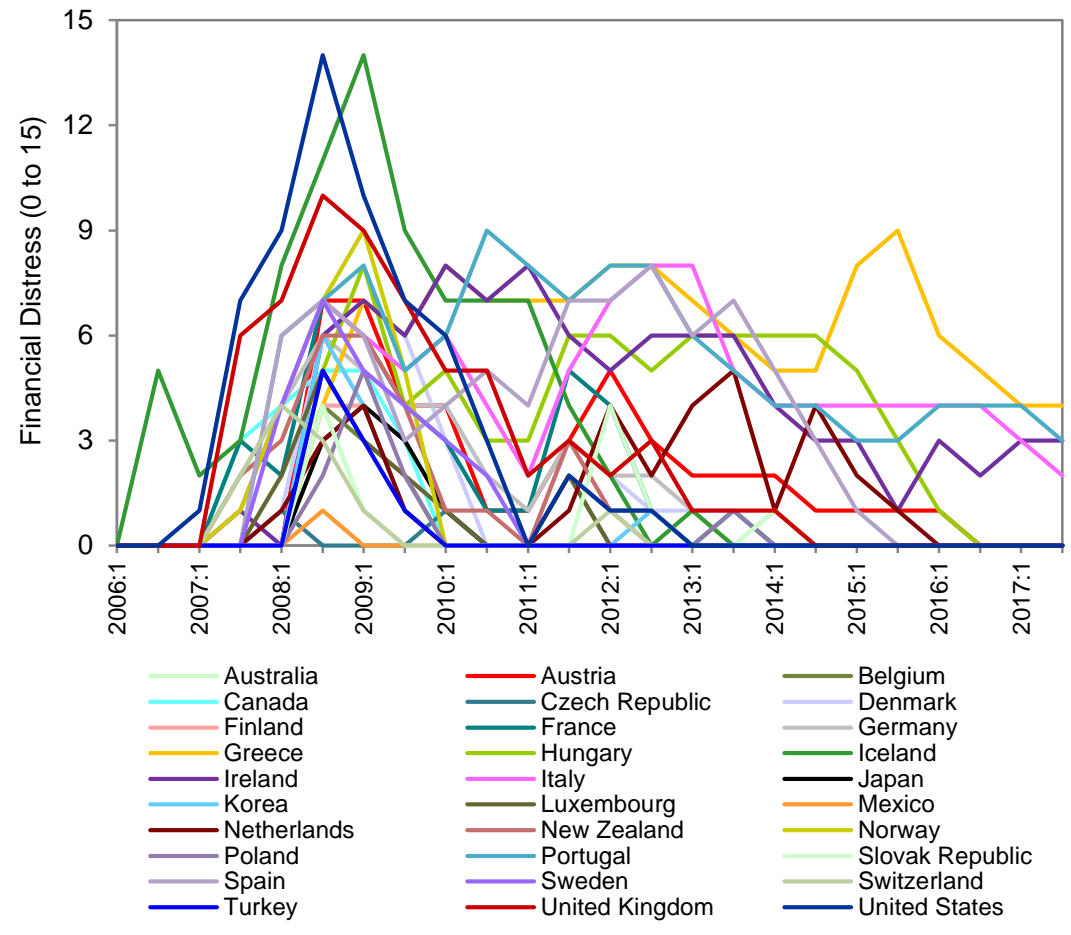

Notes: The figure shows semiannual values for the new scaled measure of financial distress for 30 OECD countries. See the text and online Appendix A for details of the derivation of the measure. 
FIGURE 2

Behavior of Real GDP after a Financial Crisis

a. Full Sample (30 Countries) and Original Sample (24 Countries)

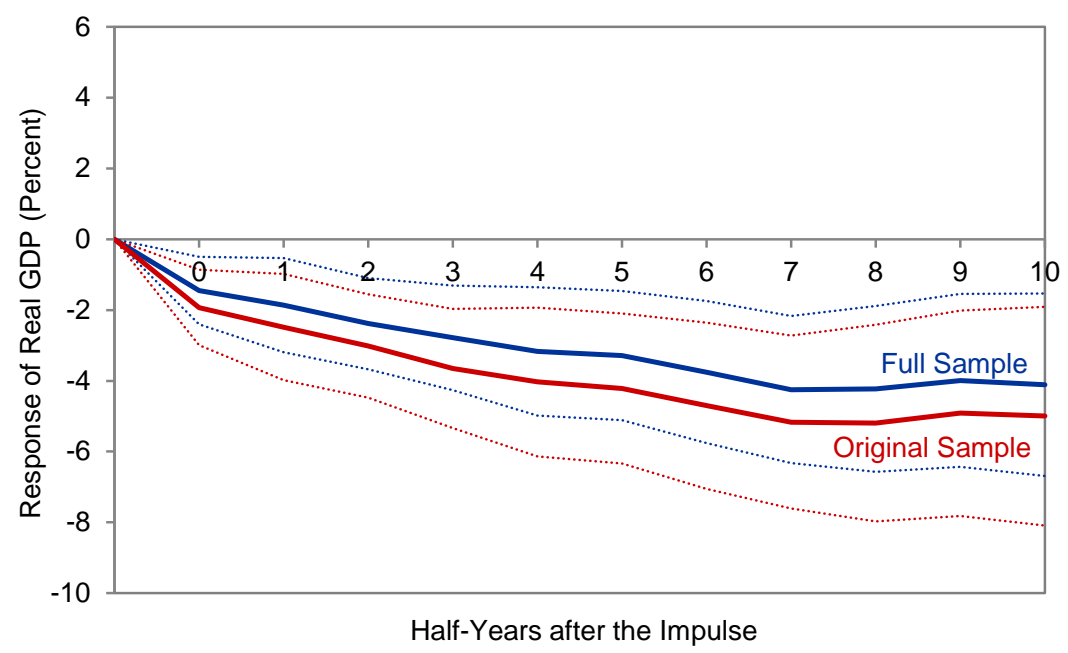

b. Samples of Countries Richer and Poorer than Greece

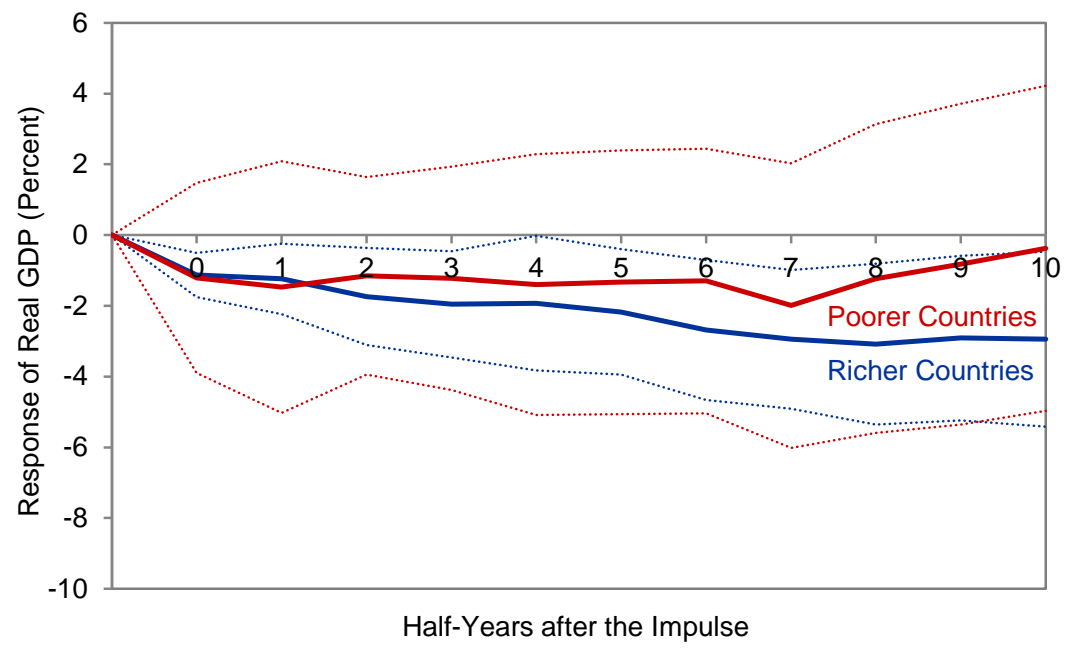

Notes: The figure shows the impulse response function of real GDP to an impulse of 7 in financial distress based on estimation of equation (1) over the period 1980:1-2017:2 for different samples of countries. The dotted lines show the two-standard-error confidence bands. 
FIGURE 3

GDP Forecast Errors for Episodes of High Financial Distress

\section{a. Cases with Positive or Small Negative Forecast Errors}

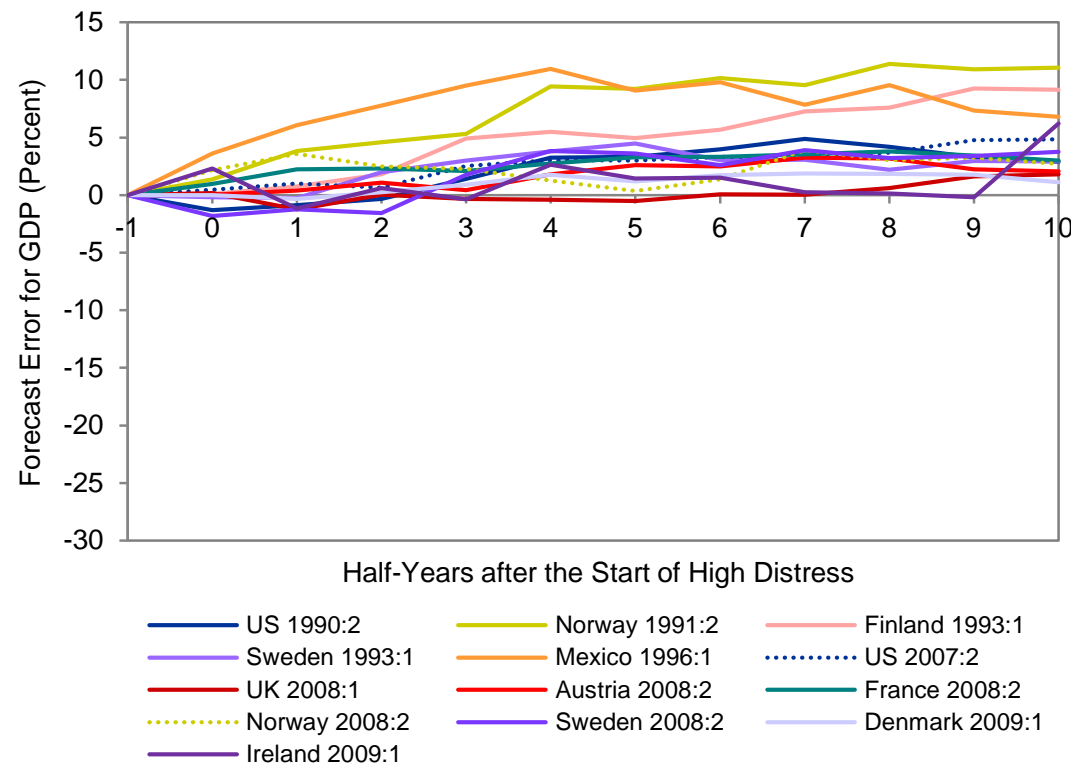

b. Cases with Substantial Negative Forecast Errors

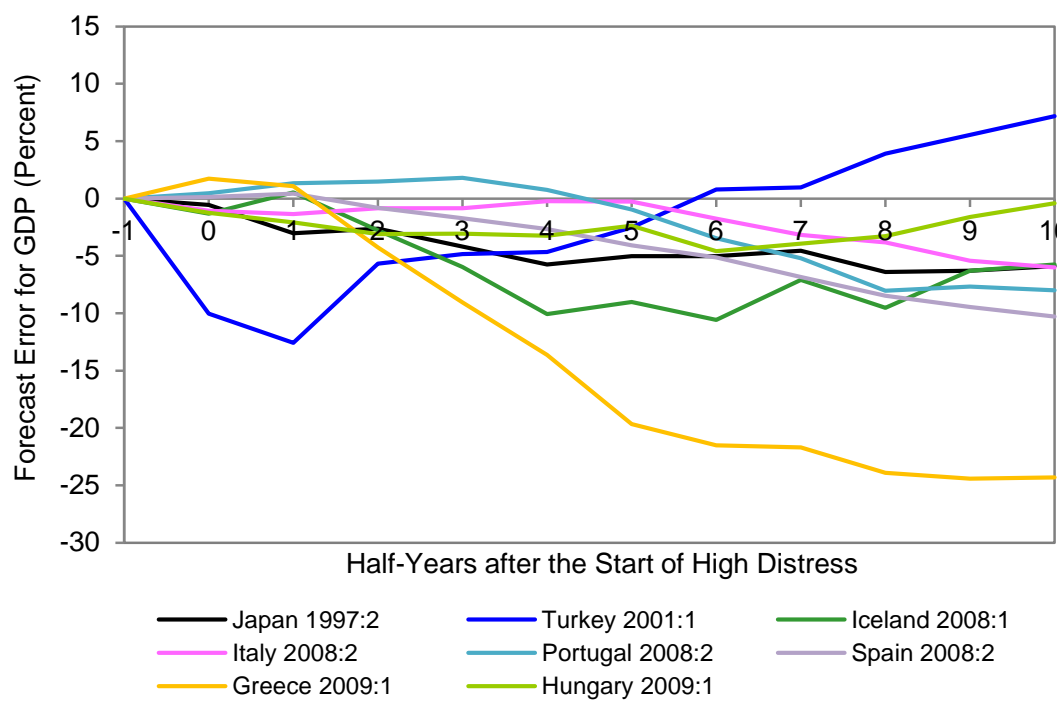

Notes: The figures show the forecast errors for real GDP based on estimation of equation (1) over the period 1980:12017:2. Forecast errors are shown for the 21 episodes where distress reached 7 or above and sufficient lags are available to construct the forecasts. The forecasts use the realization of the distress variable up through the half-year that it reached 7 or higher, and actual GDP up through one half-year before that occurs. The dates given are when distress first reached 7 or above. 
FIGURE 4

Relationship between Real GDP after a Financial Crisis and Fiscal Space

\section{a. Scaled Coefficient on the Interaction between Debt-to-GDP and Financial Distress}

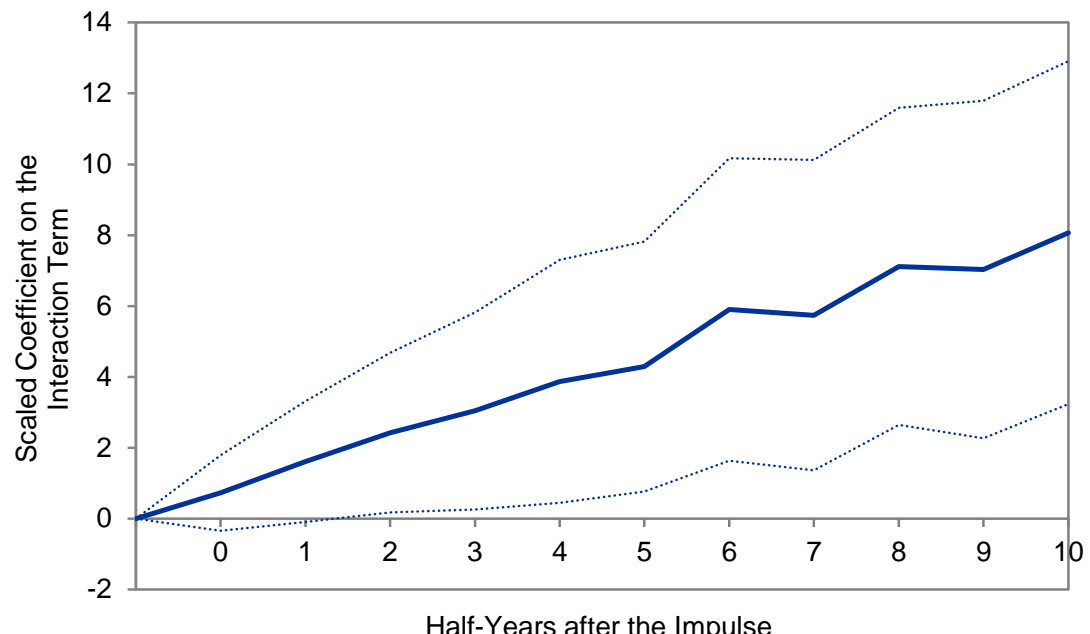

b. Response of GDP with More and Less Fiscal Space

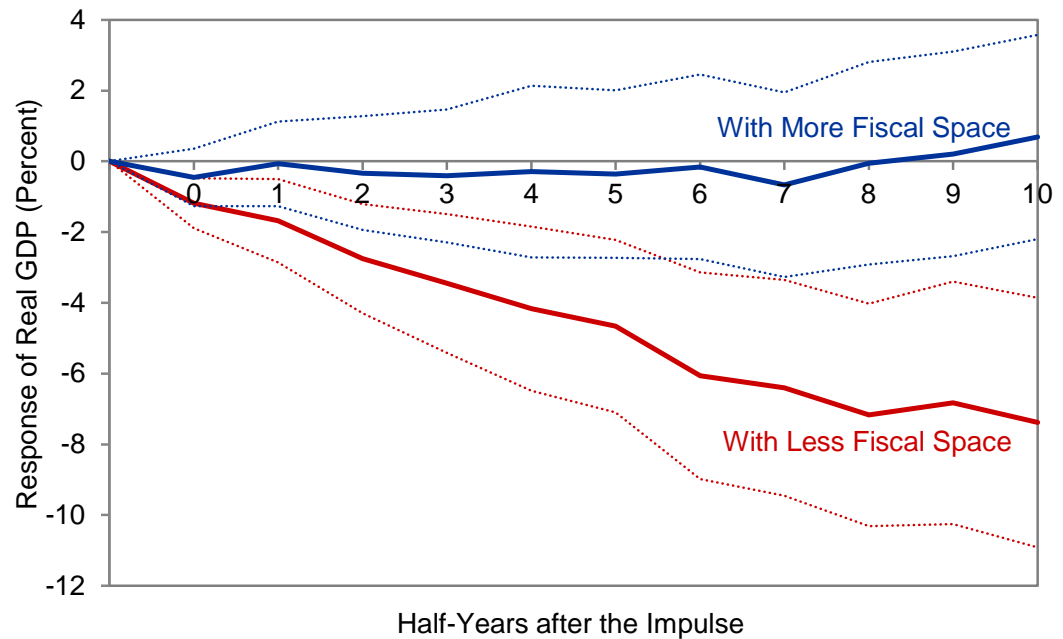

Notes: The figure is based on estimates of equation (2) over the period 1980:1-2017:2. Panel (a) shows the estimated values of $\delta^{h}$ for different values of $h$, scaled by 7 times twice the sample standard deviation of the gross debt-to-GDP ratio. Panel (b) shows the implied impulse response functions of real GDP to an impulse of 7 in financial distress for a country with a debt-to-GDP ratio in the previous calendar year one standard deviation below the sample mean ("with more fiscal space"), and for a country with a debt ratio one standard deviation above the sample mean ("with less fiscal space"). The dotted lines show the two-standard-error confidence bands. 


\section{FIGURE 5}

\section{Relationship between the High-Employment Surplus after a Financial Crisis and Fiscal Space}

\section{a. Scaled Coefficient on the Interaction between Debt-to-GDP and Financial Distress}

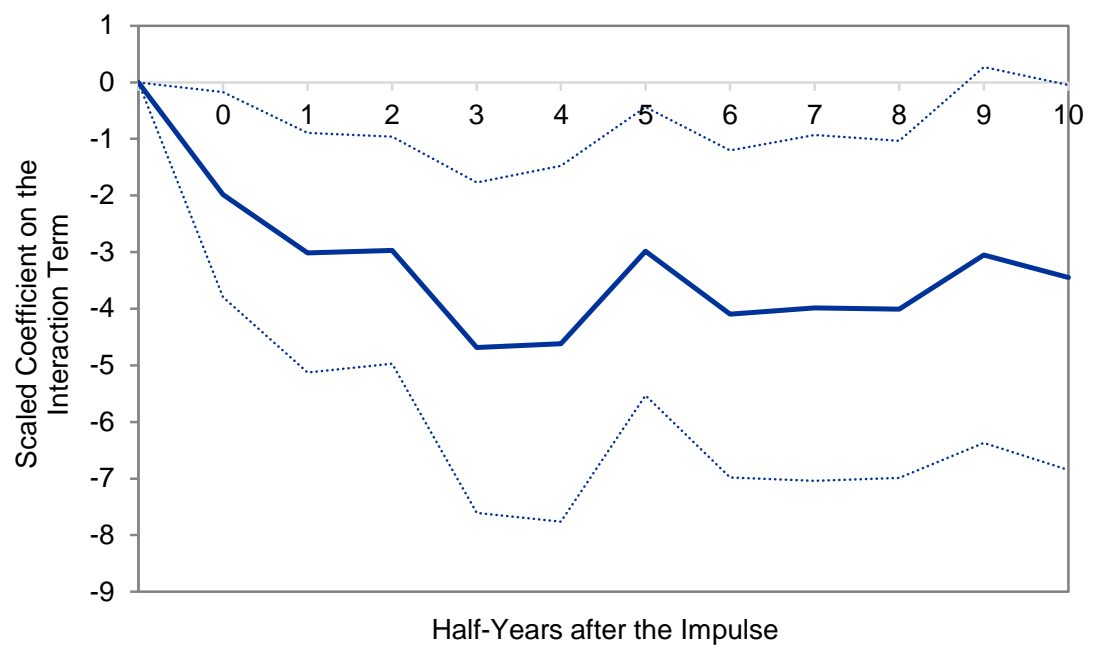

b. Response of the High-Employment Surplus with More and Less Fiscal Space

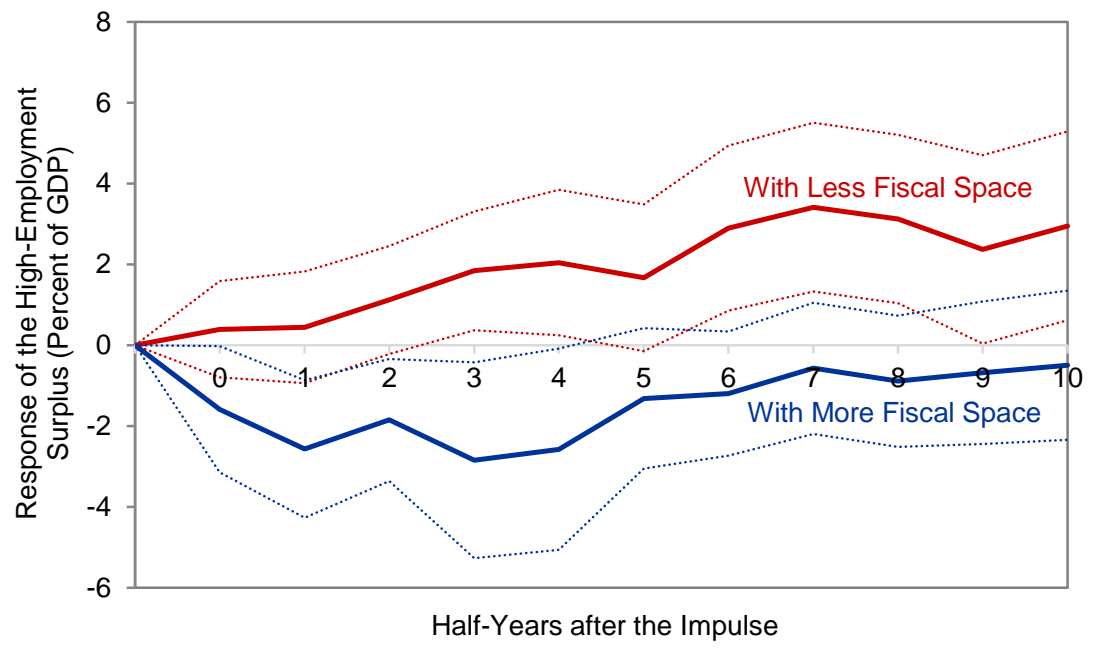

Notes: The figure is based on estimates of equation (3) over the period 1980:1-2017:2. Panel (a) shows the estimated values of $\delta^{h}$ for different values of $h$, scaled by 7 times twice the sample standard deviation of the gross debt-to-GDP ratio. Panel (b) shows the implied impulse response functions of the high-employment surplus to an impulse of 7 in financial distress for a country with a debt-to-GDP ratio in the previous calendar year one standard deviation below the sample mean ("with more fiscal space"), and for a country with a debt ratio one standard deviation above the sample mean ("with less fiscal space"). The dotted lines show the two-standard-error confidence bands. 


\section{FIGURE 6}

Financial Distress, Debt, and the High-Employment Surplus in Episodes of High Distress: Some Conforming Cases with Consistent Debt

a. Italy (2008:2)

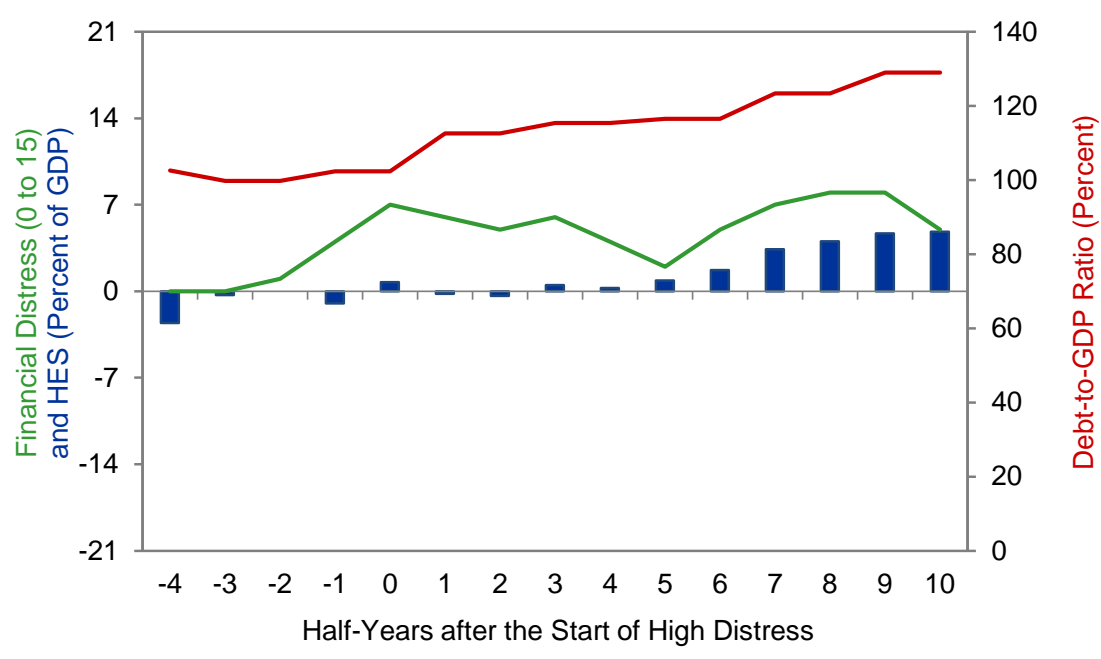

b. Norway (1991:2)

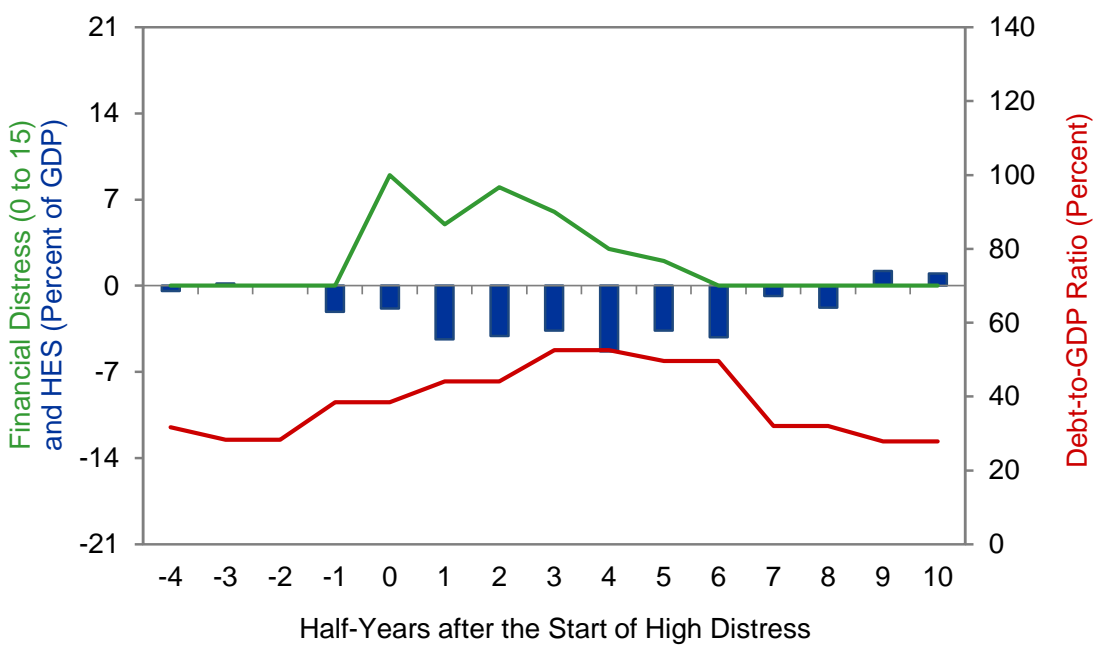

Notes: The figure shows the behavior in selected episodes of high financial distress of financial distress (green line, left axis), the change in the estimated high-employment surplus from its value two half-years before distress reached 7 or more (blue bars, left axis), and the debt-to-GDP ratio (red line, right axis). Panel (a) shows a case where debt was high throughout the episode; panel (b) shows a case where it was low throughout the episode. 
FIGURE 7

Financial Distress, Debt, and the High-Employment Surplus in Episodes of High Distress: Some Conforming Cases with Evolving Debt
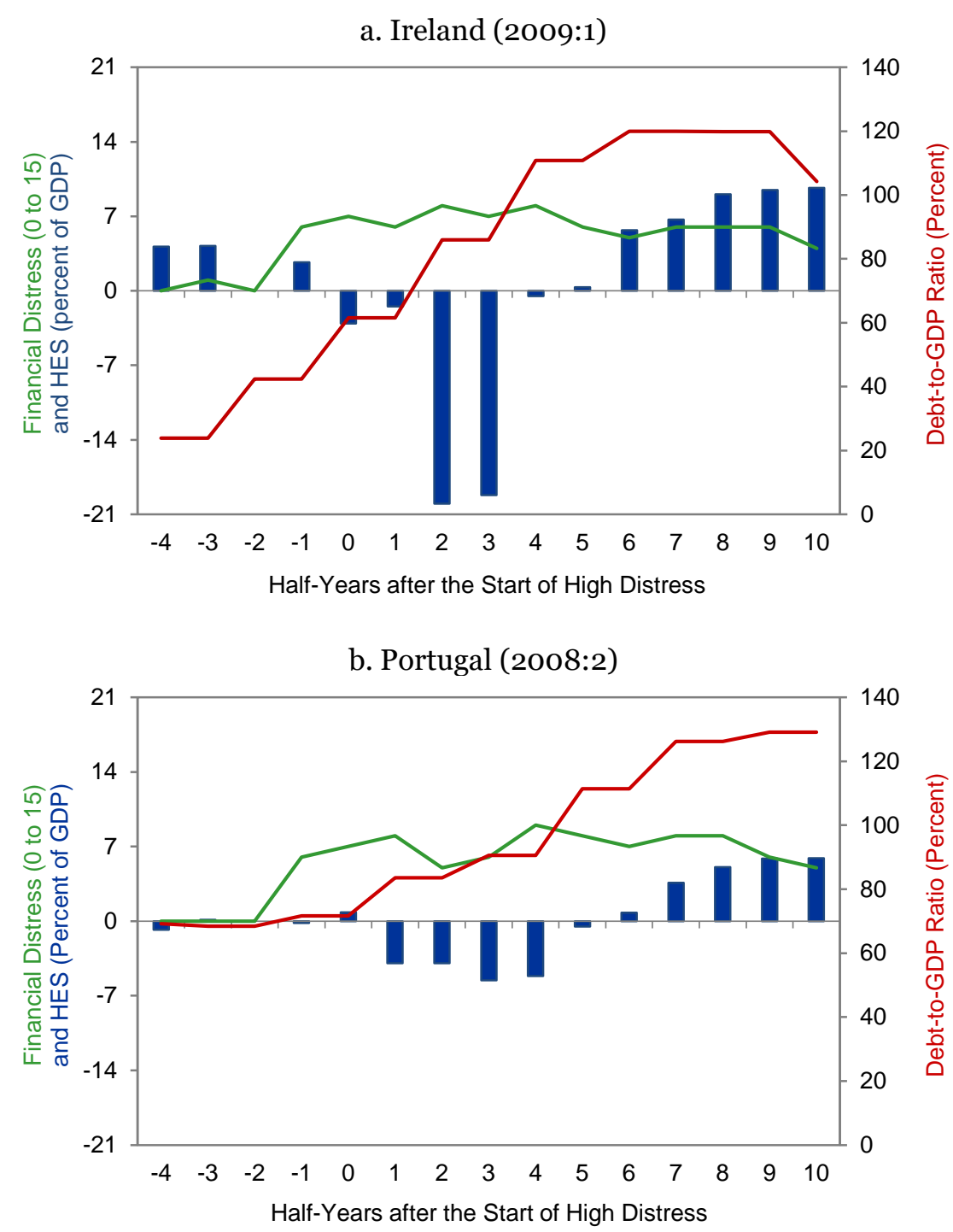

Notes: The figure shows the behavior in selected episodes of high financial distress of financial distress (green line, left axis), the change in the estimated high-employment surplus from its value two half-years before distress reached 7 or more (blue bars, left axis), and the debt-to-GDP ratio (red line, right axis). The two cases shown are ones where the debt-to-GDP ratio rose over the course of the episode and fiscal policy was first expansionary and then moved in a contractionary direction. 
FIGURE 8

Relationship between the High-Employment Surplus after a Financial Crisis and Individual Direct Measures of Sovereign Market Access

a. CDS Spread

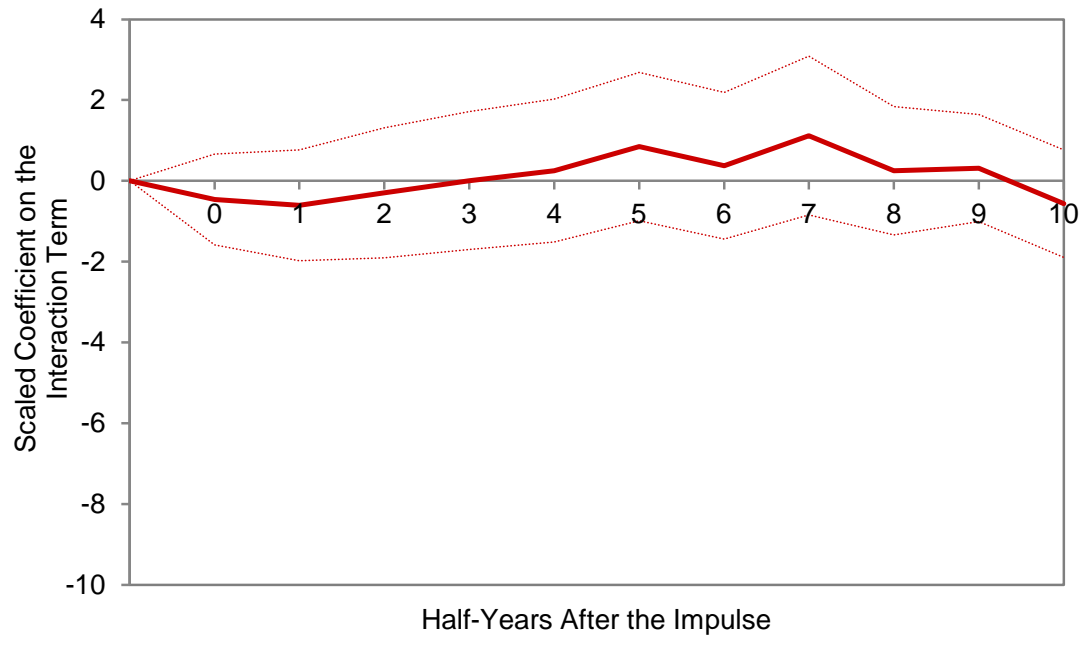

b. Long-Term Government Bond Rate

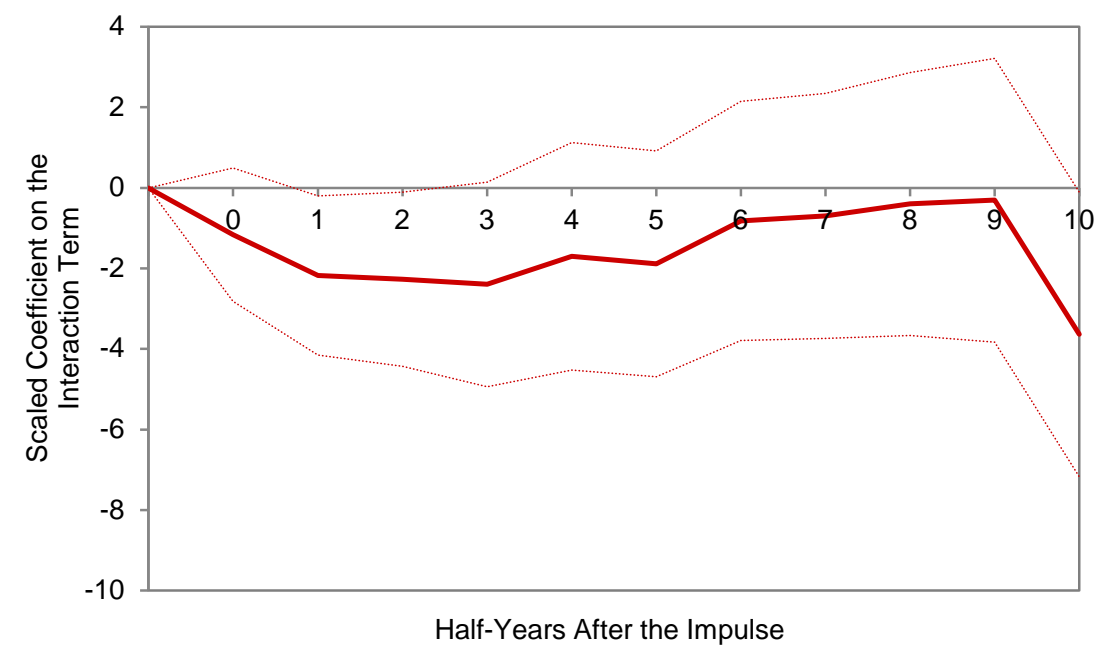


FIGURE 8 (continued)

\section{Relationship between the High-Employment Surplus after a Financial Crisis and Individual Direct Measures of Sovereign Market Access}

c. S\&P Rating

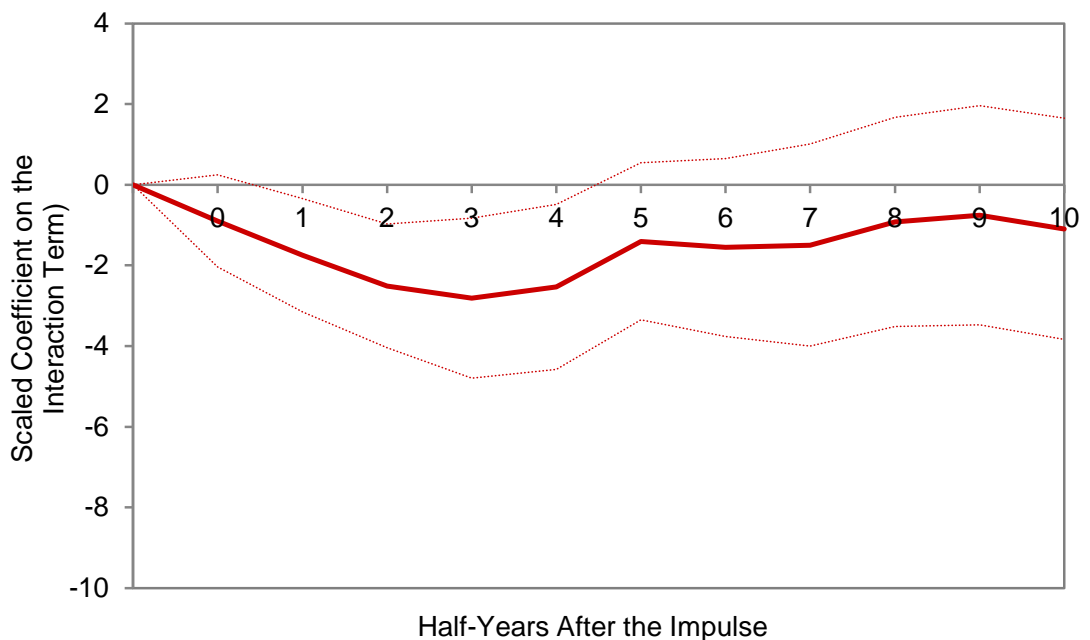

d. IMF Program

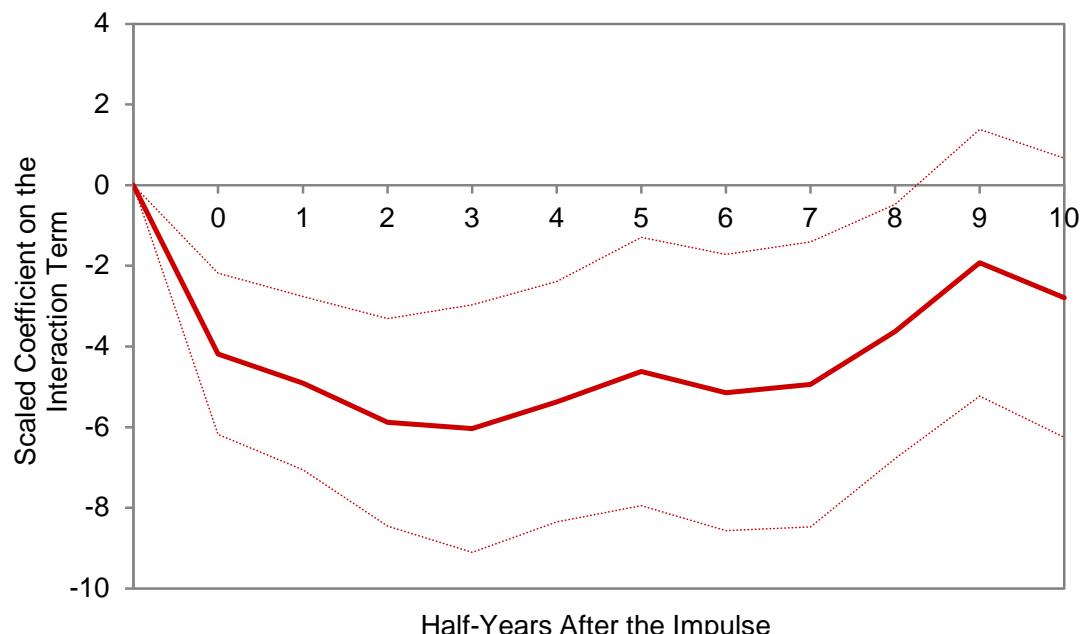

Notes: The panels show how the response of fiscal policy to financial distress varies with individual direct measures sovereign market access. Each panel is based on estimates of equation (4) over the period 1980:1-2017:2 using a different measure of market access. Panels (a), (b), and (c) show the estimated values of $\lambda^{h}$ for different values of $h$, scaled by 7 times twice the sample standard deviation of the relevant measure of market access. Thus, they show how the response to an innovation of 7 in financial distress changes with an improvement of two standard deviations in the indicated measure of access. Panel (d) shows the estimated values of $\lambda^{h}$ for different values of $h$, scaled by 7 . Thus, it shows how the response differs between a country not subject to an IMF program and a country subject to a program. The dotted lines show the two-standard-error confidence bands. 
FIGURE 9

Relationship between the High-Employment Surplus after a Financial Crisis and Multiple Direct Measures of Sovereign Market Access

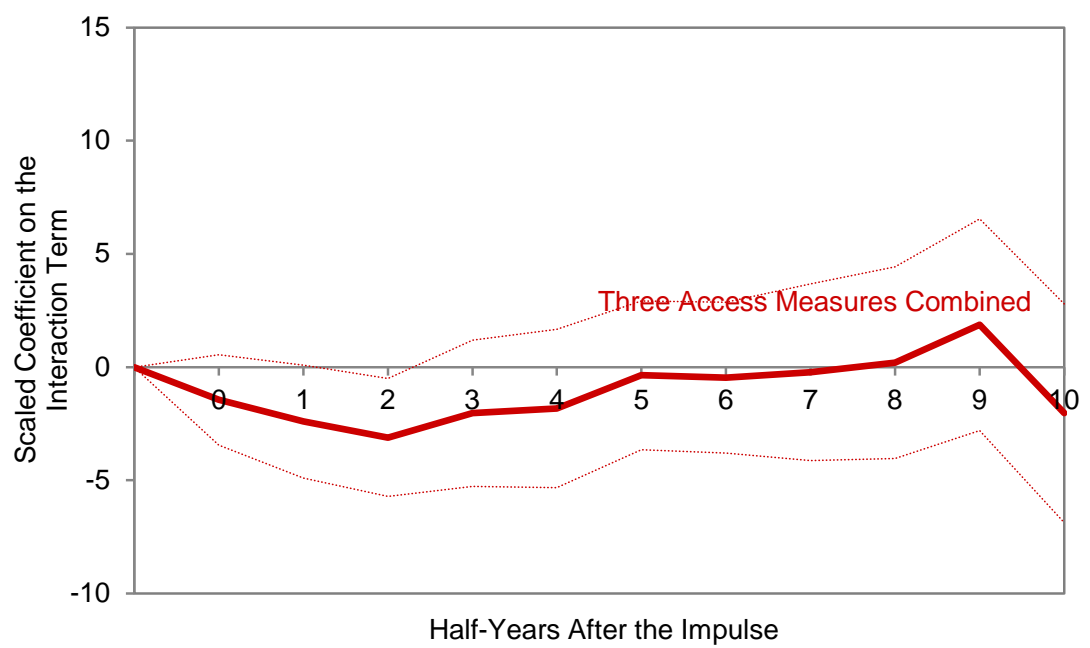

Notes: The figure shows the how the response of fiscal policy to financial distress varies with sovereign market access when several measures of market access are considered jointly. It is based on estimates of equation (4) over the period 1980:1-2017:2 including three measures of market access (the long-term government bond rate, the S\&P rating, and a dummy variable for not being under an IMF program). The figure plots the sum of the interaction term for each measure of market access times twice its standard deviation. The sum is then multiplied by 7 so that it shows how the response to an innovation of 7 in financial distress changes with an improvement of two standard deviations in all three measures of market access. The dotted lines show the two-standard-error confidence bands. 
FIGURE 10

Relationship between the High-Employment Surplus after a Financial Crisis and Both Individual Direct Measures of Sovereign Market Access and Fiscal Space

a. CDS Spread

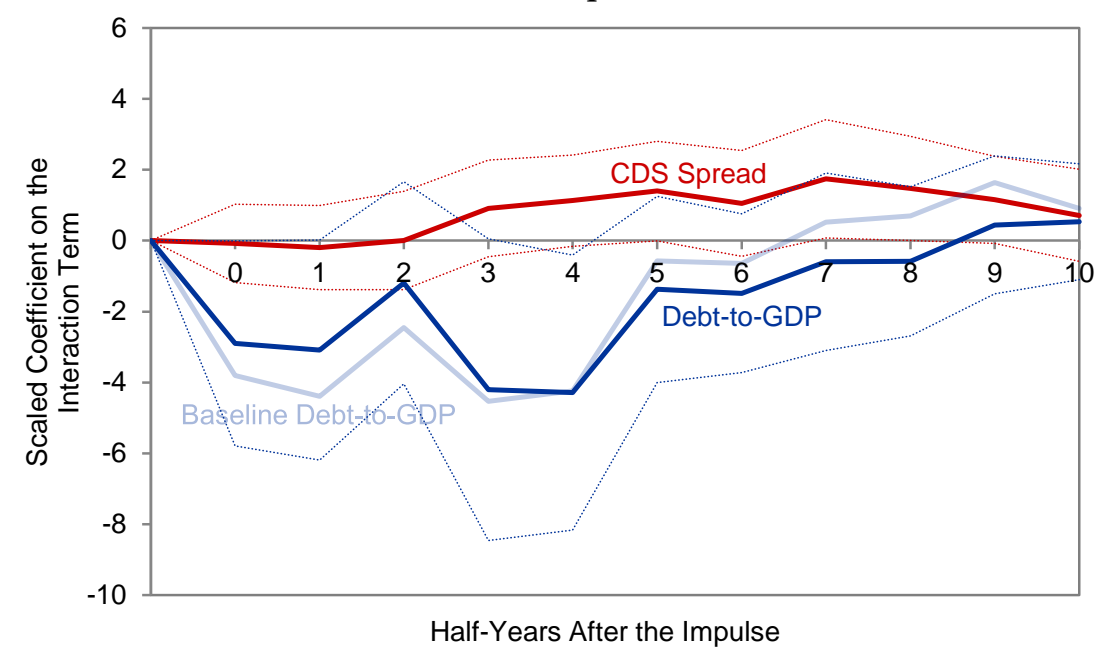

b. Long-Term Government Bond Rate

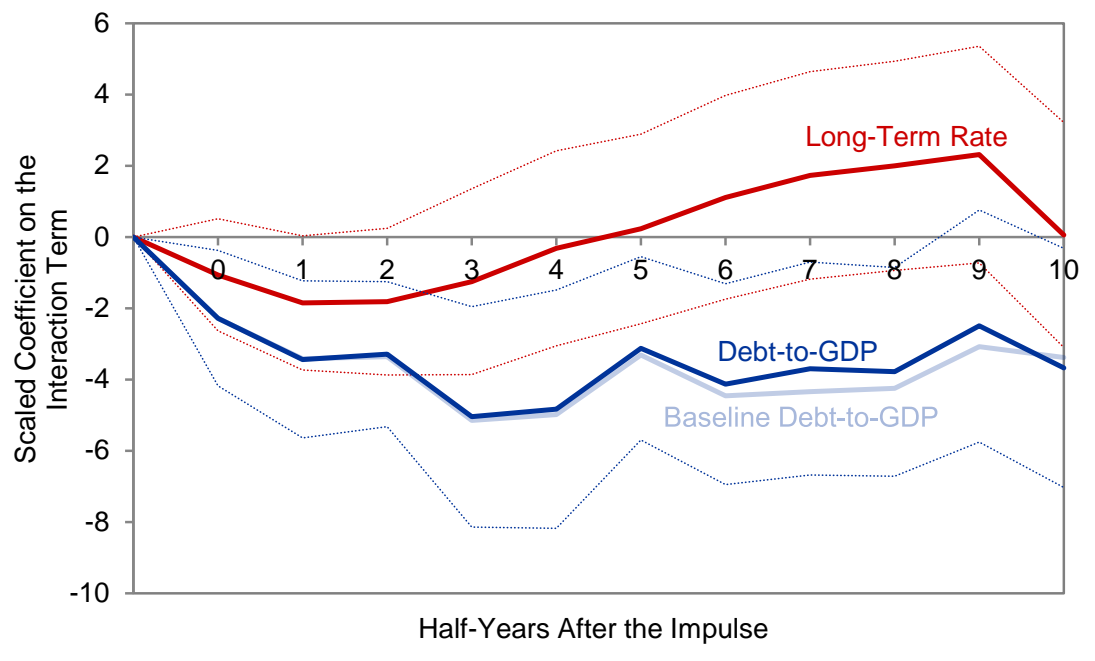




\section{FIGURE 10 (continued) \\ Relationship between the High-Employment Surplus after a Financial Crisis and Both Individual Direct Measures of Sovereign Market Access and Fiscal Space}
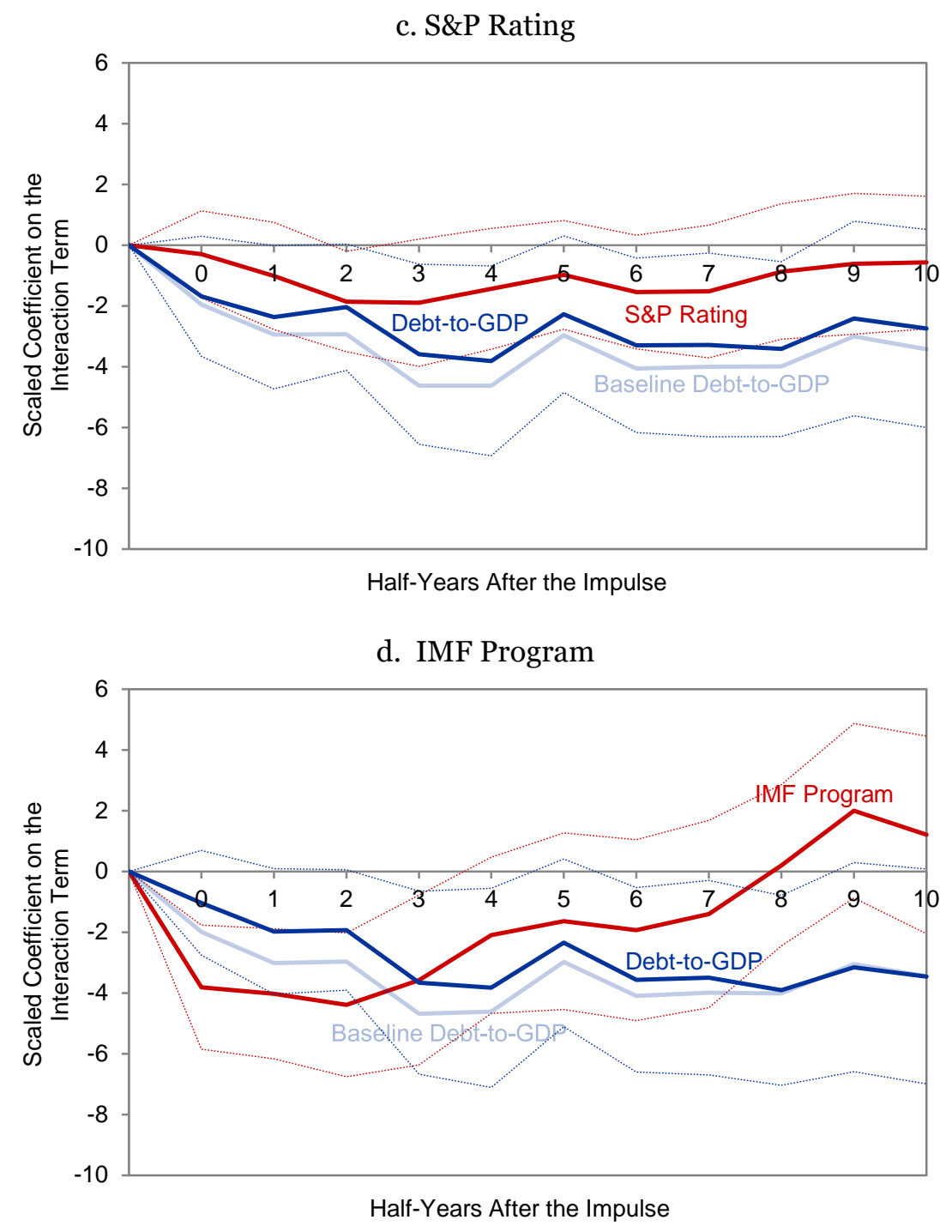

Notes: The panels show how the response of fiscal policy to financial distress varies with individual direct measures of sovereign market access, based on a specification that also includes the debt-to-GDP ratio and its interaction with financial distress. Each panel is based on estimates of equation (5) over the period 1980:1-2017:2 using a different measure of market access. Panels (a), (b), and (c) show the estimated values of $\lambda^{h}$ for different values of $h$, scaled by 7 times twice the sample standard deviation of the relevant measure of market access. Thus, they show how the response to an innovation of 7 in financial distress changes with an improvement of two standard deviations in the indicated measure of access. Panel (d) shows the estimated values of $\lambda^{h}$ for different values of $h$, scaled by 7 . Thus, it shows how the response differs between a country not subject to an IMF program and a country subject to a program. Each panel also shows the estimated values of $\delta^{h}$ for different values of $h$, scaled by 7 times twice the sample standard deviation of the debt ratio. Thus it shows how the response changes with a decline of two standard deviations in the debt-to-GDP in the specification including the indicated measure of market access and its interaction with financial distress. The pale line denoted "baseline debt-to-GDP" shows how the response changes with a decline of two standard deviations in the debt-to-GDP ratio in the specification excluding the measure of market access (but using the same sample period as the expanded regression). The dotted lines show the twostandard-error confidence bands. 


\section{FIGURE 11}

\section{Relationship between the High-Employment Surplus after a Financial Crisis and Both Multiple Direct Measures of Sovereign Market Access and Fiscal Space}

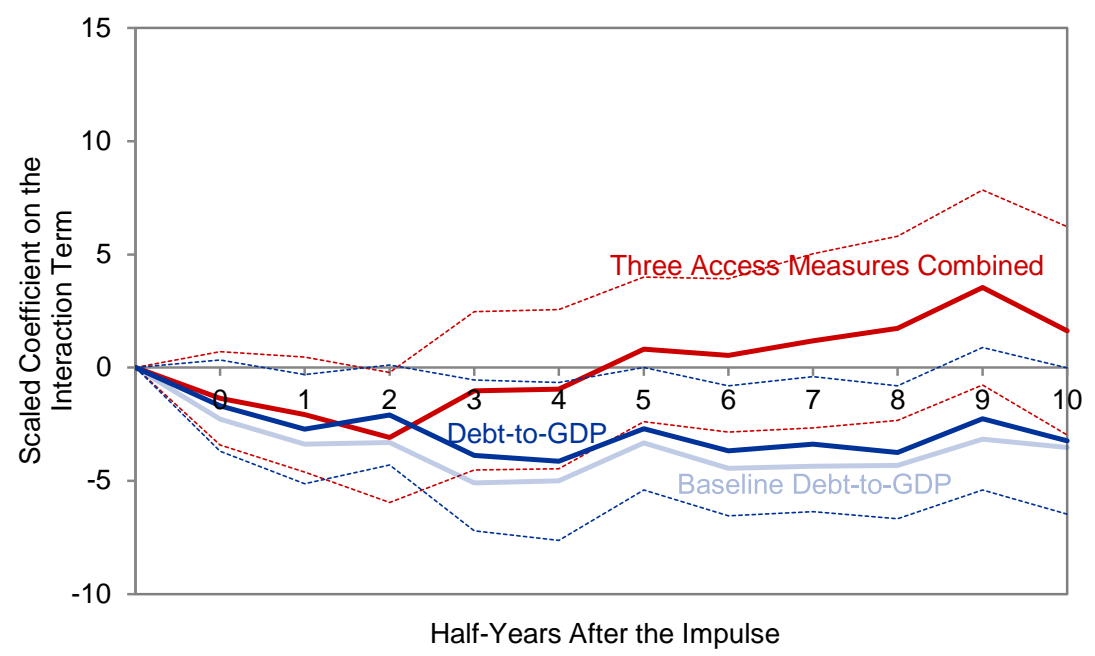

Notes: The figure shows how the response of fiscal policy to financial distress varies with measures of sovereign market access when several measures of market access are considered jointly, and the specification also includes the debt-to-GDP ratio and its interaction with financial distress. The figure is based on estimates of equation (5) over the period 1980:1-2017:2 including three measures of market access (the long-term government bond rate, the S\&P rating, and the dummy variable for not being under an IMF program). The figure plots the sum of the interaction term for each measure of market access times twice its standard deviation. The sum is then multiplied by 7 so that it shows how the response to an innovation of 7 in financial distress changes with an improvement of two standard deviations in all three measures of market access. The figure also shows how the response changes with a decline of two standard deviations in the debt-to-GDP in the specification including the three measures of market access and their interaction with financial distress. The pale line denoted "baseline debt-to-GDP" shows how the response changes with a decline of two standard deviations in the debt-to-GDP ratio in the specification excluding the measures of market access (but using the same sample period as the expanded regression). The dotted lines show the two-standard-error confidence bands. 
TABLE 1

Financial Distress in OECD Countries, 2013:1-2017:2

(and in the Added Countries Starting when Information is Available)

\begin{abstract}
Austria
2013:1 Credit disrupt.-reg.

2013:2 Credit disrupt.-reg.

2014:1 Credit disrupt.-reg.

2014:2 Credit disrupt.-minus

2015:1 Credit disrupt.-minus

2015:2 Credit disrupt.-minus

2016:1 Credit disrupt.-minus
\end{abstract}

\section{Czech Republic}

2008:1 Credit disrupt.-minus

2010:1 Credit disrupt.-minus

\section{Denmark}

2013:1 Credit disrupt.-minus 2013:2 Credit disrupt.-minus

\section{France}

2013:2 Credit disrupt.-minus

\section{Germany}

2013:1 Credit disrupt.-minus

2014:1 Credit disrupt.-minus

\section{Greece}

2013:1 Moderate crisis-minus 2013:2 Minor crisis-plus 2014:1 Minor crisis-reg. 2014:2 Minor crisis-reg. 2015:1 Moderate crisis-reg. 2015:2 Moderate crisis-plus 2016:1 Minor crisis-plus 2016:2 Minor crisis-reg. 2017:1 Minor crisis-minus 2017:2 Minor crisis-minus

\section{Hungary}

2008:2 Minor crisis-reg. 2009:1 Moderate crisis-reg. 2009:2 Minor crisis-minus 2010:1 Minor crisis-reg. 2010:2 Credit disrupt.-plus 2011:1 Credit disrupt.-plus 2011:2 Minor crisis-plus 2012:1 Minor crisis-plus 2012:2 Minor crisis-reg. 2013:1 Minor crisis-plus 2013:2 Minor crisis-plus 2014:1 Minor crisis-plus 2014:2 Minor crisis-plus 2015:1 Minor crisis-reg.
Hungary (continued)

2015:2 Credit disrupt.-plus

2016:1 Credit disrupt.-minus

\section{Iceland}

2013:1 Credit disrupt.-minus

\section{Ireland}

2013:1 Minor crisis-plus 2013:2 Minor crisis-plus 2014:1 Minor crisis-minus 2014:2 Credit disrupt.-plus 2015:1 Credit disrupt.-plus 2015:2 Credit disrupt.-minus 2016:1 Credit disrupt.-plus 2016:2 Credit disrupt.-reg. 2017:1 Credit disrupt.-plus 2017:2 Credit disrupt.-plus

\section{Italy}

2013:1 Moderate crisis-reg. 2013:2 Minor crisis-reg. 2014:1 Minor crisis-minus 2014:2 Minor crisis-minus 2015:1 Minor crisis-minus 2015:2 Minor crisis-minus 2016:1 Minor crisis-minus 2016:2 Minor crisis-minus 2017:1 Credit disrupt.-plus 2017:2 Credit disrupt.-reg.

\section{Korea}

1997:1 Credit disrupt.-plus 1997:2 Moderate crisis-reg. 1998:1 Major crisis-minus 1998:2 Moderate crisis-plus 1999:1 Moderate crisis-reg. 1999:2 Moderate crisis-minus 2000:1 Credit disrupt.-plus 2000:2 Minor crisis-reg. 2001:1 Minor crisis-plus 2001:2 Minor crisis-minus 2002:1 Credit disrupt.-plus 2003:2 Minor crisis-minus 2004:1 Minor crisis-plus 2004:2 Credit disrupt.-plus 2005:1 Credit disrupt.-minus 2008:2 Minor crisis-plus 2009:1 Minor crisis-minus 2009:2 Credit disrupt.-minus 2012:2 Credit disrupt.-minus

\section{Mexico \\ 1995:2 Minor crisis-plus 1996:1 Moderate crisis-minus 1996:2 Minor crisis-reg. 1997:1 Credit disrupt.-reg. 1997:2 Minor crisis-minus 1998:1 Credit disrupt.-reg. 2008:2 Credit disrupt.-minus}

\section{Netherlands \\ 2013:1 Minor crisis-minus 2013:2 Minor crisis-reg. 2014:1 Credit disrupt.-minus 2014:2 Minor crisis-minus 2015:1 Credit disrupt.-reg. 2015:2 Credit disrupt.-minus}

\section{Poland}

2008:2 Credit disrupt.-reg. 2009:1 Minor crisis-reg. 2009:2 Credit disrupt.-reg. 2011:2 Credit disrupt.-reg. 2012:1 Credit disrupt.-minus 2012:2 Credit disrupt.-minus 2013:2 Credit disrupt.-minus

\section{Portugal}

2013:1 Minor crisis-plus 2013:2 Minor crisis-reg. 2014:1 Minor crisis-minus 2014:2 Minor crisis-minus 2015:1 Credit disrupt.-plus 2015:2 Credit disrupt.-plus 2016:1 Minor crisis-minus 2016:2 Minor crisis-minus 2017:1 Minor crisis-minus 2017:2 Credit disrupt.-plus

\section{Slovak Republic}

2008:2 Minor crisis-minus 2009:1 Credit disrupt.-minus 2012:1 Minor crisis-minus 2012:2 Credit disrupt.-minus 2014:1 Credit disrupt.-minus

\section{Spain}

2013:1 Minor crisis-plus 2013:2 Moderate crisis-minus 2014:1 Minor crisis-reg. 2014:2 Credit disrupt.-plus 2015:1 Credit disrupt.-minus 


\section{United Kingdom}

2013:1 Credit disrupt.-minus

2013:2 Credit disrupt.-minus

2014:1 Credit disrupt.-minus

Notes: The table shows the non-zero values for our scaled measure of financial distress for 30 OECD countries from 2013:1 to 2017:2. It also shows all non-zero values for the six countries added to the sample going back to when they enter the sample (2003:2 for the Czech Republic, 1998:1 for Hungary, 1996:2 for Korea, 1994:1 for Mexico, 1998:1 for Poland, and 2003:2 for the Slovak Republic). See the text and online Appendix A for details of the derivation of the measure. For the values of the measure of financial distress for the original 24 countries in our sample for 1967:1 to 2012:2, see Romer and Romer (2017, Table 1, pp. 3081-82). 
TABLE 2

Summary of the Motivations for Fiscal Actions Following Financial Crises as Described in the Economist Intelligence Unit Country Reports

\begin{abstract}
(Crisis episodes in chronological order;
date given is the half-year in which financial distress first reached 7 or above)

United States (1990:2)

Fiscal policy in the U.S. was basically moderately contractionary throughout. It was driven by two ideas of domestic policymakers. One was that deficits and debt were bad and that the deficit needed to be reduced. The other was that short-run stabilization was best left to monetary policy, which freed fiscal policy to focus on the long-run fiscal outlook and other long-run issues. There was a tiny bit of fiscal expansion in 1992 driven by countercyclical and political motivations.
\end{abstract}

Norway (1991:2)

Norway undertook moderately expansionary fiscal policy until well after the crisis for countercyclical purposes and financial rescue. Policy then turned mildly contractionary. The shift was partly the result of policymakers' belief that fiscal rectitude was desirable (despite Norway's extremely strong fiscal position), and partly a countercyclical response to strong growth.

Finland (1993:1)

Finland initially undertook a large fiscal expansion for financial rescue. Otherwise, fiscal policy was contractionary throughout, often strongly so. The first contractionary moves stemmed from policymakers' beliefs that deficit reduction and low debt were beneficial. Later, a desire to join the EMU was also important. Market access was mentioned, but was confined to two reports and emphasized only in one.

\title{
Sweden (1993:1)
}

There was much fiscal expansion in Sweden for financial rescue early on. This expansion was partly counterbalanced by austerity on other fronts owing to a mixture of ideas (the Conservative-led government wanted to shrink the welfare state) and concern about spreads (so a form of market access). Fiscal policy then switched to net austerity. Ideas played a role after the change in government in 1994: the new government also supported getting the budget under control and the electorate seemed to support that. Later on, a desire to meet EU criteria was an important motivation for continued austerity.

\section{Mexico (1996:1)}

There was substantial financial rescue in Mexico, but on net fiscal policy was contractionary throughout, at times strongly so. The main motivation for the austerity was a blend of market access and IMF conditionality. Market access was a substantial problem and the government was trying to regain the confidence of investors and satisfy the IMF. There was also an element of ideas at the end of the period. The outgoing president wanted to prevent a crisis at the handover of government in 2000, and so wanted to run careful policy to prevent trouble.

\section{Japan (1997:2)}

Japan engaged in at least modest fiscal expansion throughout the post-crisis period. Initially, it undertook some fiscal stimulus for countercyclical reasons and financial rescue (though ideas about the importance of fiscal rectitude may have limited actions). In mid-1998, a new government came in and did more aggressive stimulus and financial rescue. There was a little concern about market access that may have restrained stimulus, but it did not lead to austerity. Political considerations and countercyclical aims were the main motivations for continued fiscal expansion later in the post-crisis period.

\section{Korea (1997:2)}

Korea initially engaged in some fiscal contraction due to IMF conditionality and problems with market access. Pretty quickly there was a move toward modest fiscal expansion driven by countercyclical aims, financial rescue, and political considerations. Eventually the government shifted to roughly neutral fiscal policy as the economy recovered. 


\section{Turkey (2001:1)}

Turkey engaged in substantial financial rescue, especially early on. But, this was followed by strong austerity. It is hard to separate market access and IMF conditionality as the motivation for the austerity. Lack of market access led to the IMF program; once in place, the IMF conditionality was strictly enforced (both by the IMF and by markets). At times politics and ideas led policymakers to suggest less austerity. Later in the analysis period, Turkey's desire to join the EU was also a driving force for fiscal contraction.

\section{United States (2007:2)}

Fiscal policy in the U.S. was initially highly expansionary for countercyclical purposes and financial rescue. It then leveled out and finally turned slightly contractionary. Policymakers' ideas about the harms of the debt and deficits in their own right, plus some concerns about market access (specifically, long-term interest rates and bond ratings), limited the expansionary actions and prompted the ultimate move to contraction.

\section{Iceland (2008:1)}

Iceland initially engaged in a large fiscal expansion related to financial rescue. Then, there was substantial fiscal contraction due to loss of market access and subsequent IMF and Nordic conditionality. The IMF, however, did not force much contraction in 2009 , when the recession was at its worst. There was a small continuing role for market access in fostering austerity because ratings on sovereign debt affected borrowing costs of municipalities and companies. Also there may have been a small role for domestic policymakers' own ideas-at times the government seemed to go further with austerity than the IMF required. In addition, there was a fight within the governing coalition, suggesting again that ideas mattered.

\section{United Kingdom (2008:1)}

The U.K. spent a substantial amount on financial rescue, but did only a very small amount of fiscal stimulus. With Cameron's election in May 2010, the government switched to extreme austerity. The government said that future market access was the reason, but the EIU emphasized that actual market access was excellent. This juxtaposition may suggest an important role for ideas.

\section{Austria (2008:2)}

Fiscal policy in Austria was initially mildly expansionary for countercyclical reasons and financial rescue, but there was then a switch to substantial austerity. The change appeared to result roughly equally from EU rules and from domestic policymakers' ideas about the benefits of fiscal rectitude.

\section{France (2008:2)}

France initially undertook mildly expansionary fiscal policy for countercyclical purposes and financial rescue. But the size was limited, and policy soon switched to austerity and then remained mildly contractionary. The limitations on the size of the initial expansion and the initial move to austerity were driven mainly by domestic policymakers' ideas about the benefits of fiscal restraint. But market access issues and EU rules both played nontrivial roles in the continued austerity.

\section{Italy (2008:2)}

Italy engaged in only trivial fiscal stimulus and little financial rescue in the post-crisis period. This was followed by moderate austerity for a number of years. A key reason for the austerity was problems with market access and rising sovereign spreads. EU rules and pressure were another factor, and there was perhaps a small role for domestic ideas toward the end of the analysis period.

\section{Norway (2008:2)}

Policymakers in Norway undertook moderate fiscal expansion in response to the crisis, motivated by both countercyclical aims and financial rescue. The EIU thought Norway's oil revenues and low debt were reasons it could do this. The government then scaled back the stimulus in response to recovery to prevent the economy from overheating, but it never switched to net austerity. 
Portugal (2008:2)

Portugal initially engaged in mildly expansionary policy for countercyclical purposes (with just a small amount of financial rescue). Political considerations in the run-up to the election also played a role in driving fiscal expansion. EU rules and actions were a factor in the early moves toward austerity. Starting in mid-2010, Portugal lost the confidence of foreign investors. Lack of market access followed by IMF conditionality led to extreme austerity. The austerity and conditionality continued through the end of the analysis period.

\section{$\underline{\text { Spain (2008:2) }}$}

Spain initially engaged in mildly expansionary fiscal policy for countercyclical reasons and financial rescue. But policy then turned strongly contractionary and remained so. The main reason was market access, as Spain faced high sovereign spreads and ratings downgrades. Toward the end of the period, the problems with market access led to the possibility of Spain needing to turn to outside help, which created additional pressures for austerity. There were some indications of a role for domestic policymakers' ideas, but those were never central.

\section{$\underline{\text { Sweden (2008:2) }}$}

Despite its comparatively small-government, supply-side ideology, the Swedish government pursued moderately expansionary fiscal policy throughout, for both financial rescue and, especially, countercyclical reasons. The EIU thought that Sweden's initial surplus and low debt were important reasons such expansion was feasible. The degree of stimulus was adjusted (in both directions) in response to the state of the economy.

\section{Denmark (2009:1)}

Denmark initially pursued slightly expansionary fiscal policy for countercyclical reasons and financial rescue. But policy then turned generally moderately contractionary. The switch stemmed mainly from policymakers' ideas about the benefits of fiscal responsibility, with a secondary role for EU rules. There was only one minor mention of concern about market access.

\section{Greece (2009:1)}

Greece's initial fiscal policy response consisted of a small expansion for financial rescue and small conventional fiscal actions in both directions driven by a range of motivations, with at most a small net fiscal expansion. But policy soon turned to austerity, which became increasingly severe over time. The initial turn to austerity stemmed from a combination of EU rules and issues with market access, with hints of a role for domestic policymakers' ideas. The later, harsher austerity came about as Greece lost market access and then turned to international organizations for aid, which came with strong conditionality.

\section{Hungary (2009:1)}

Despite a small initial bank rescue, fiscal policy in Hungary was on net contractionary throughout, often strongly so. It was initially driven mainly by conditionality associated with an IMF-led program that predated the crisis. Later, it was driven mainly by concerns about market access, with some role for attempting to obtain renewed IMF support. A desire to comply with EU rules in order to join the euro played a role at times, but was never central.

\section{Ireland (2009:1)}

Ireland initially engaged in extreme financial rescue, partially counteracted by austerity in other areas. A loss of market access then led to extreme overall austerity. This was followed by continued austerity to comply with the conditionality of the IMF/EU bailout. Conditionality remained central through the end of the analysis period.

Notes: See Online Appendix B for the detailed notes and quotations from the Economist Intelligence Unit Country Reports on which the summaries are based. 
TABLE 3

Size and Motivations for Fiscal Expansions in Episodes of High Financial Distress

\section{a. Size}

(Date expansion is first mentioned in parentheses)

\begin{tabular}{l}
\multicolumn{1}{c}{ Small } \\
\hline U.S. (1992Q1) ${ }^{\mathrm{b}}$ \\
Norway (1991Q4) \\
Korea (1999Q1) \\
Austria (2009M1) \\
France (2009M1) \\
Italy (2009M1) \\
Norway (2009M1) \\
Portugal (2009M1) \\
Spain (2009M1) \\
Sweden (2009M1) \\
Denmark (2009M7) \\
Greece (2009M7)
\end{tabular}

$\frac{1}{c}$ Large
Finland (1993Q1)
Sweden (1993Q2)
Japan (19981)
Turkey (2001M7)
U.S. (2008M7)
Iceland (2009M1)
U.K. (2009M1)
Ireland (2009M7)

b. Motivation

(Date motivation is first mentioned in parentheses)

\begin{tabular}{|c|c|c|}
\hline Financial Rescue & Countercyclical & Politics \\
\hline & $\overline{\text { U.S. }(1992 Q 1)^{f}}$ & $\overline{\text { U.S. }(1992 Q 1)^{f}}$ \\
\hline Norway (1991Q4) & Norway (1991Q4) & Norway $(1993 Q 1)^{f}$ \\
\hline \multicolumn{3}{|l|}{ Finland (1993Q1) } \\
\hline \multicolumn{3}{|l|}{ Sweden (1993Q2) } \\
\hline Japan (1998Q1) & Japan (1998Q1) & $\operatorname{Japan}(1998 Q 1)^{f}$ \\
\hline Korea $(1999 Q 1)^{d}$ & Korea (1999Q1) & Korea $\left(1999\right.$ Q3) ${ }^{f}$ \\
\hline \multicolumn{3}{|l|}{ Turkey (2001M7) } \\
\hline U.S. (2009M1) & U.S. $(2008 \mathrm{M} 7)$ & \\
\hline \multicolumn{3}{|l|}{ Iceland $(2009 \mathrm{M} 1)$} \\
\hline U.K. (2009M1) & U.K. $(2009 \mathrm{M} 1)^{f}$ & \\
\hline Austria (2009M1) & Austria (2009M1) & \\
\hline France $(2009 \mathrm{M} 1)^{\mathrm{f}}$ & France $(2009 \mathrm{M} 1)^{\mathrm{f}}$ & \\
\hline Italy $(2009 \mathrm{M} 1)^{\mathrm{f}}$ & Italy $(2009 \mathrm{M} 1)^{\mathrm{f}}$ & \\
\hline Norway $(2009 \mathrm{M} 1)^{\mathrm{f}}$ & Norway (2009M1) & \\
\hline Portugal (2009M1) & Portugal (2009M1) & Portugal (2009M1) \\
\hline Spain (2009M1) & Spain (2009M1) & \\
\hline Sweden (2009M1) & Sweden (2009M1) & \\
\hline Denmark (2009M7) & Denmark (2009M7) & \\
\hline Greece $(2009 \mathrm{M} 7)^{\mathrm{f}}$ & & \\
\hline Ireland $(2009 \mathrm{M} 7)$ & & \\
\hline
\end{tabular}

Notes: The results summarize the narrative evidence from the Economist Intelligence Unit Country Reports. See Online Appendix B for the detailed quotations underlying our classifications.

a Two countries had no net expansion following their crises (Mexico and Hungary).

$\mathrm{b}$ Expansion was extremely small.

${ }^{\mathrm{c}}$ Expansion was toward the moderate direction.

${ }^{\mathrm{d}}$ Korea undertook austerity first and then fiscal expansion.

e In addition, both Mexico and Hungary, which did no net fiscal expansion, undertook substantial financial rescue (combined with other austerity measures).

$\mathrm{f}_{\text {Motivation was minor. }}$ 
TABLE 4

Size and Motivations for Fiscal Austerity in Episodes of High Financial Distress

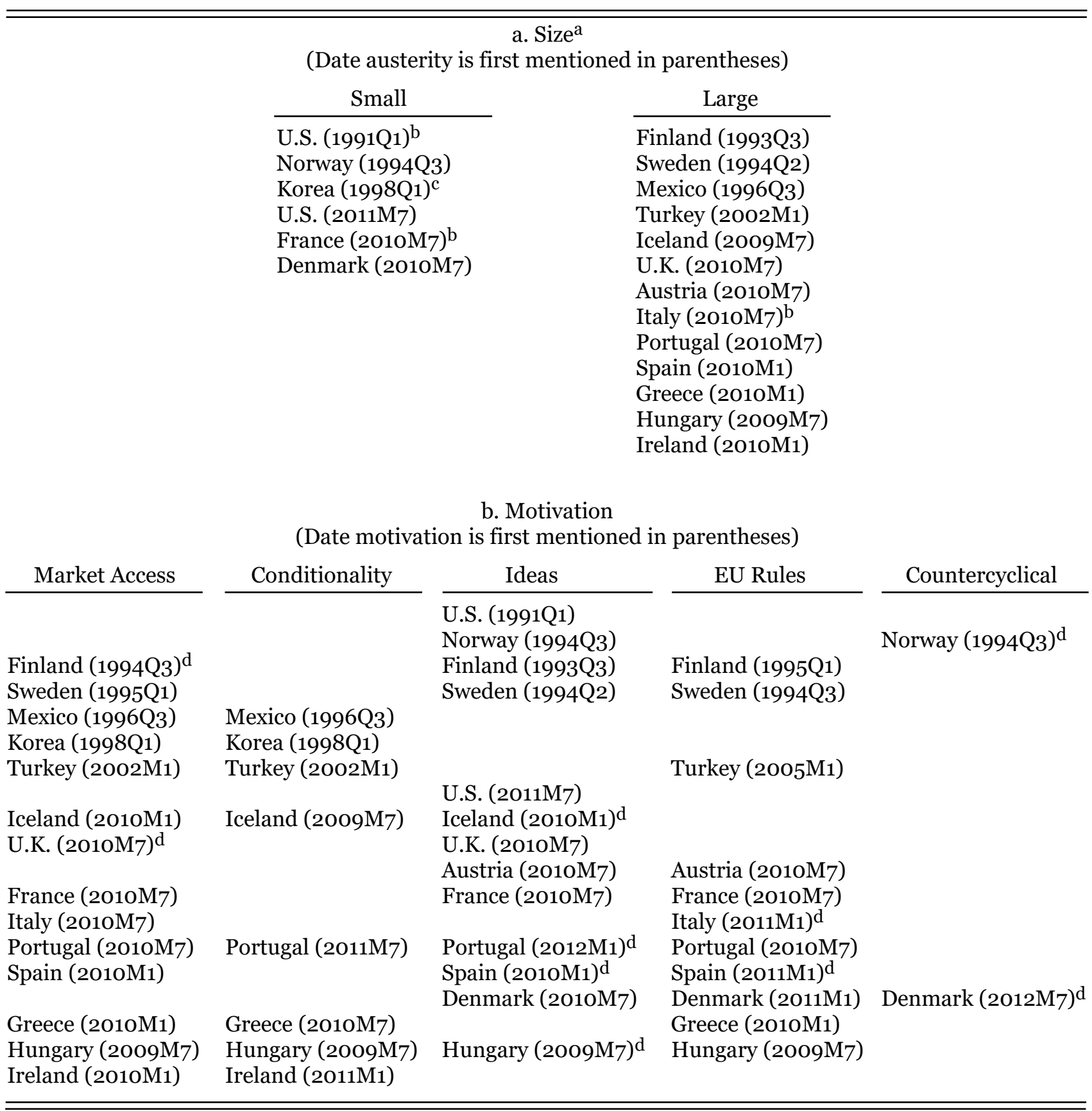

Notes: The results summarize the narrative evidence from the Economist Intelligence Unit Country Reports. See Online Appendix B for the detailed quotations underlying our classifications.

${ }^{a}$ Three countries never on net undertook austerity following their crises (Japan, Sweden 2008, and Norway 2008).

$\mathrm{b}$ Toward the moderate direction.

c Korea undertook austerity first and then fiscal expansion.

d Motivation was minor. 
TABLE 5

Narrative Evidence on the Role of Debt in Fostering Austerity or Limiting Expansion in Episodes of High Financial Distress ${ }^{\mathrm{a}}$

\begin{tabular}{|c|c|c|c|}
\hline Via Market Access & Via Conditionality & Via Ideas & Via EU Rules \\
\hline \multirow{4}{*}{ Sweden (1996Q3) } & \multirow{9}{*}{ Turkey (2002M1) } & U.S. $(1991 Q 3)^{b}$ & \\
\hline & & Finland (1993Q3) & Finland (1995Q1) \\
\hline & & Sweden (1994Q3) & Sweden (1996Q3) \\
\hline & & Japan (2000M6) & \\
\hline \multirow[t]{5}{*}{ Turkey (2003M7) } & & & \\
\hline & & U.S. $(2011 \mathrm{M} 7)^{\mathrm{b}}$ & \\
\hline & & Iceland $(2009 \mathrm{M} 1)^{\mathrm{b}}$ & \\
\hline & & U.K. (2010M7) & \\
\hline & & Austria (2010M1) & \\
\hline France (2011M1) & & France $(2010 \mathrm{M} 1)^{\mathrm{b}}$ & \\
\hline \multirow[t]{2}{*}{ Italy (2009M7) } & & & Italy (2011M1) \\
\hline & Portugal (2011M7) & & \\
\hline Spain (2010M7) & & Denmark $(2009 \mathrm{M} 7)^{\mathrm{b}}$ & \\
\hline Greece $(2009 \mathrm{M} 7)$ & Greece $(2010 M 7)$ & & \\
\hline Hungary (2010M1) & Hungary $(2011 \mathrm{M} 7)$ & & \\
\hline
\end{tabular}

Notes: The results summarize the narrative evidence from the Economist Intelligence Unit Country Reports. See Online Appendix B for the detailed quotations underlying our classifications.

a Date motivation is first mentioned in parentheses.

$\mathrm{b}$ Weaker evidence. 
TABLE 6

The Relationship between the EIU's Assessments of the Fiscal Response to a Crisis and Data on the Prior Debt Ratio

\begin{tabular}{lc}
\hline \hline EIU Description & Average Debt Ratio, $\%$ \\
Size of Expansion: & $71(1)$ \\
None & $55(12)$ \\
Small & $49(8)$ \\
Large & \\
Motivation for Expansion: & $52(19)$ \\
Financial rescue & $55(14)$ \\
Countercyclical & $57(5)$ \\
Politics & \\
Size of Austerity: & $63(3)$ \\
None & $57(6)$ \\
Small & $68(12)$ \\
Large & \\
Motivation for Austerity: & $66(13)$ \\
Market access & $68(7)$ \\
Conditionality & $65(13)$ \\
Domestic ideas & $74(11)$ \\
EU Rules & $49(2)$ \\
Countercyclical & \\
Role of Debt: & $26(3)$ \\
No role mentioned & $44(2)$ \\
Fostered expansion & $80(7)$ \\
Fostered austerity via: & $87(4)$ \\
Market access & $66(10)$ \\
Conditionality & \\
Domestic ideas & \\
EU rules & \\
\hline \hline
\end{tabular}

Notes: Debt figures are based on when developments were first mentioned by the EIU in an episode, using numbers for the previous year. The number of observations is given in parentheses. 


\section{REFERENCES}

Alesina, Alberto, and Silvia Ardagna. 2010. "Large Changes in Fiscal Policy: Taxes versus Spending." Tax Policy and the Economy 24: 35-68.

Baron, Matthew, Emil Verner, and Wei Xiong. 2018. "Equity and Banking Crises." Working paper. wxiong.mycpanel.princeton.edu/papers/BankingCrisis.pdf

Bernanke, Ben S. 1983. "Nonmonetary Effects of the Financial Crisis in the Propagation of the Great Depression." American Economic Review 73, no. 3: 257-76.

Bernardini, Marco, and Lorenzo Forni. 2018. "Private and Public Debt Interlinkages in Bad Times." Working paper. https://lorenzoforni.files.wordpress.com/2018/07/private-andpublic-debt-interlinkages-in-bad-times.pdf

Binder, Carola Conces. 2018. "Political Pressure on Central Banks." Working paper. https://papers.ssrn.com/sol3/papers.cfm?abstract id $=3244148$

Bohn, Henning. 1998. "The Behavior of U.S. Public Debt and Deficits." Quarterly Journal of Economics, 113, no. 3, 949-63.

Bordo, Michael, Barry Eichengreen, Daniela Klingebiel, and Maria Soledad Martinez-Peria. 2001. “Is the Crisis Problem Growing More Severe?” Economic Policy 16, no. 32: 51-82.

Chodorow-Reich, Gabriel. Forthcoming. "Geographic Cross-Sectional Fiscal Spending Multipliers: What Have We Learned?” American Economic Journal: Economic Policy.

Chodorow-Reich, Gabriel, Laura Feiveson, Zachary Liscow, and William Gui Woolston. 2012. "Does State Fiscal Relief During Recessions Increase Employment? Evidence from the American Recovery and Reinvestment Act." American Economic Journal: Economic Policy 4, no. 3: 118-45.

Economist Intelligence Unit. Various years. Country Reports. London: Economist Intelligence Unit Limited.

Elmendorf, Douglas. 2016. "Recommendations for Federal Fiscal Policy." Speech delivered at the Federal Reserve Bank of San Francisco. https://www.hks.harvard.edu/more/aboutus/leadership-administration/offices-deans/deans-office/presentations-andpapers/recommendations-for-federal-fiscal-policy

Fisher, Jonas D. M., and Ryan Peters. 2010. "Using Stock Returns to Identify Government Spending Shocks." Economic Journal 120, no. 544: 414-36.

Ghosh, Atish R., Jun I. Kim, Enrique G. Mendoza, Jonathan D. Ostry, and Mahvash S. Qureshi. 2013. "Fiscal Fatigue, Fiscal Space and Debt Sustainability in Advanced Economies." Economic Journal 123, no. 566: F4-F30.

Girouard, Nathalie, and Christophe André. 2005. "Measuring Cyclically-Adjusted Budget Balances for OECD Countries.” OECD Economics Department Working Paper No. 434. 
Guajardo, Jaime, Daniel Leigh, and Andrea Pescatori. 2014. "Expansionary Austerity? International Evidence." Journal of the European Economic Association 12, no. 4: 949968.

Ilzetzki, Ethan, Enrique G. Mendoza, and Carlos A. Végh. 2013. "How Big (Small?) Are Fiscal Multipliers?” Journal of Monetary Economics 60, no. 2: 239-54.

International Monetary Fund. 2018. IFS World and Country Notes Yearbook 2018. Washington, DC: International Monetary Fund.

Jordà, Òscar, Moritz Schularick, and Alan M. Taylor. 2016. "Sovereigns versus Banks: Credit, Crises, and Consequences." Journal of the European Economic Association 14, no. 1: 4579.

Kose, M. Ayhan, Sergio Kurlat, Franziska Ohnsorge, and Naotaka Sugawara. 2017. "A CrossCountry Database of Fiscal Space.” World Bank Development Prospects Group, Policy Research Working Paper no. 8157.

Laeven, Luc, and Fabián Valencia. 2014. "Systemic Banking Crises." In Financial Crises: Causes, Consequences, and Policy Responses, edited by Stijn Claessens, M. Ayhan Kose, Luc Laeven, and Fabián Valencia, 61-137. Washington, DC: International Monetary Fund.

Mendoza, Enrique G., and Jonathan D. Ostry. 2008. "International Evidence on Fiscal Solvency: Is Fiscal Policy ‘Responsible’?” Journal of Monetary Economics 55, no. 6: 1081-93.

Obstfeld, Maurice. 2013. "On Keeping Your Powder Dry: Fiscal Foundations of Financial and Price Stability.” Monetary and Economic Studies 31, no. 1: 25-38.

Organisation for Economic Co-Operation and Development (OECD). Various years. OECD Economic Outlook. Paris: OECD Publishing.

Nakamura, Emi, and Jón Steinsson. 2014. "Fiscal Stimulus in a Monetary Union: Evidence from U.S. Regions.” American Economic Review 104, no. 3: 753-92.

Perotti, Roberto. 1999. "Fiscal Policy in Good Times and Bad.” Quarterly Journal of Economics 114, no. 4: 1399-436.

Ramey, Valerie A. 2011. "Identifying Government Spending Shocks: It's All in the Timing." Quarterly Journal of Economics 126, no. 1: 1-50.

Ramey, V. A. 2016. "Macroeconomic Shocks and Their Propagation.” In John B. Taylor and Harald Uhlig, eds., Handbook of Macroeconomics, Vol. 2 (Amsterdam: Elsevier), 71-162.

Reinhart, Carmen M., and Kenneth S. Rogoff. 2009. This Time Is Different: Eight Centuries of Financial Folly. Princeton, NJ: Princeton University Press.

Reinhart, Carmen M., and Kenneth S. Rogoff. 2010. "Growth in a Time of Debt." American Economic Review 100, no. 2: 573-78.

Romer, Christina D., and David H. Romer. 2010. "The Macroeconomic Effects of Tax Changes: Estimates Based on a New Measure of Fiscal Shocks.” American Economic Review 100, no. 3: 763-801. 
Romer, Christina D., and David H. Romer. 2017. "New Evidence on the Aftermath of Financial Crises in Advanced Economies." American Economic Review 107, no. 10: 3072-118.

Romer, Christina D., and David H. Romer. 2018. "Why Some Times Are Different: Macroeconomic Policy and the Aftermath of Financial Crises." Economica 85, no. 337: 140 .

Suárez Serrato, Juan Carlos, and Philippe Wingender. 2016. "Estimating Local Fiscal Multipliers.” National Bureau of Economic Research Working Paper No. 22425. 